\title{
Carbon Sources in the Sediments of a Restoring vs. Historically Unaltered Salt Marsh
}

\author{
Judith Z. Drexler ${ }^{1} \cdot$ Melanie J. Davis ${ }^{2,3} \cdot$ Isa Woo $^{4} \cdot$ Susan De La Cruz ${ }^{4}$ \\ Received: 3 December 2019 / Revised: 9 April 2020 / Accepted: 14 April 2020 / Published online: 22 April 2020 \\ (C) The Author(s) 2020
}

\begin{abstract}
Salt marshes provide the important ecosystem service of carbon storage in their sediments; however, little is known about the sources of such carbon and whether they differ between historically unaltered and restoring systems. In this study, stable isotope analysis was used to quantify carbon sources in a restoring, sparsely vegetated marsh (Restoring) and an adjacent, historically unaltered marsh (Reference) in the Nisqually River Delta (NRD) of Washington, USA. Three sediment cores were collected at "Inland" and "Seaward" locations at both marshes $\sim 6$ years after restoration. Benthic diatoms, C3 plants, C4 plants, and particulate organic matter (POM) were collected throughout the NRD. $\delta^{13} \mathrm{C}$ and $\delta^{15} \mathrm{~N}$ values of sources and sediments were used in a Bayesian stable isotope mixing model to determine the contribution of each carbon source to the sediments of both marshes. Autochthonous marsh C3 plants contributed $73 \pm 10 \%\left(98 \mathrm{~g} \mathrm{C} \mathrm{m}^{-2}\right.$ year $\left.^{-1}\right)$ and $89 \pm 11 \%\left(119 \mathrm{~g} \mathrm{C} \mathrm{m}^{-2} \mathrm{year}^{-1}\right)$ to Reference-Inland and Reference-Seaward sediment carbon sinks, respectively. In contrast, the sediment carbon sink at the Restoring Marsh received a broad assortment of predominantly allochthonous materials, which varied in relative contribution based on source distance and abundance. Marsh POM contributed the most to Restoring-Seaward $(42 \pm 34 \%)\left(69 \mathrm{~g} \mathrm{C} \mathrm{m}^{-2} \mathrm{year}^{-1}\right)$ followed by Riverine POM at Restoring-Inland (32 $\pm 41 \%)\left(52 \mathrm{~g} \mathrm{C} \mathrm{m}^{-2}\right.$ year $\left.^{-1}\right)$. Overall, this study demonstrates that largely unvegetated, restoring marshes can accumulate carbon by relying predominantly on allochthonous material, which comes mainly from the most abundant and closest estuarine sources.
\end{abstract}

Keywords Carbon-13 $\cdot$ Carbon sequestration $\cdot$ Carbon market $\cdot$ Nitrogen-15 $\cdot$ Salt marsh $\cdot$ Stable isotope mixing model $\cdot$ Wetland restoration

Communicated by Carolyn A. Currin

Electronic supplementary material The online version of this article (https://doi.org/10.1007/s12237-020-00748-7) contains supplementary material, which is available to authorized users.

Judith Z. Drexler

jdrexler@usgs.gov

1 U.S. Geological Survey, California Water Science Center, $6000 \mathrm{~J}$ Street, Placer Hall, Sacramento, CA 95819, USA

2 U.S. Geological Survey, Western Ecological Research Center, Olympia Substation, 100 Brown Farm Road Northeast, Olympia, WA 98516, USA

3 School of Aquatic and Fishery Sciences, University of Washington, 1122 Northeast Boat Street, Seattle, WA 98105, USA

4 U.S. Geological Survey, Western Ecological Research Center, P.O. Box 158, Moffett Field, CA 94035, USA

\section{Introduction}

The ultimate goal of wetland restoration is to re-establish the components, functions, and values of a wetland so that it matches or nearly matches those of a historically unaltered "reference" wetland (Craft 2016a). In salt marsh restoration, appropriate plant colonization is crucial not only for establishing habitat for shorebirds, nekton, and other coastal wildlife but also for developing highly valued ecosystem services such as nutrient cycling and carbon storage (Craft 2016b). Early in the process, most restored salt marshes contain little to no appropriate vegetation, but usually native plant colonization occurs within the first 5 years (Wolters et al. 2008; Erfanzadeh et al. 2010; Craft 2016b). However, some restoring marshes remain sparsely vegetated for years, decades, or even longer (Craft 2016b). Lack of plant colonization can be attributed to several factors including low initial elevation due to improper grading or landsurface subsidence, poor drainage, or post-restoration issues such as compaction and anoxia (Orr et al. 2003; Mossman et al. 2012; Brooks et al. 2015). Due to their slow restoration 
trajectories, such salt marshes represent novel transitional ecosystems, where the term "novel" most broadly denotes ecosystems with biotic and/or abiotic characteristics altered by human agency (Chapin and Starfield 1997; but see also Hobbs et al. 2009, 2013). Numerous examples of such novel transitional systems have been described in the literature (e.g., Haltiner et al. 1997; Portnoy 1999; Orr et al. 2003; Garbutt et al. 2006; Mossman et al. 2012; Poppe and Rybczyk 2019).

As salt marsh restoration becomes increasingly intertwined with the carbon market (Crooks et al. 2019; Vanderklift et al. 2019), it becomes important to consider whether restoring salt marshes have the capacity to store carbon in their sediments, a function typically provided by mature "blue carbon" ecosystems (coastal ecosystems including salt marshes, mangroves, and seagrasses with atmospherically significant and manageable carbon stocks and fluxes; McLeod et al. 2011; Duarte et al. 2013; Windham-Myers et al. 2019). However, little is currently known about the carbon storage potential of such novel transitional ecosystems (but see Drexler et al. 2019), raising several important questions. For example, how can a restoring salt marsh store organic carbon if it is largely unvegetated? This is only likely if the marsh is a repository for allochthonous sources of carbon (Howe and Simenstad 2007; Howe and Simenstad 2015) or has high autochthonous productivity of benthic algae (Duarte 2017) and if site geomorphology is conducive to sediment accumulation (Rabenhorst 2001). In addition, what is the particular provenance of the carbon sources contributing to the carbon sink in these marshes? This is a more difficult question to answer as it depends on the hydrodynamics of the marsh, its proximity to other systems, and the sources of carbon that are found in the study area, factors that are also important for carbon sources in marsh food webs (Howe and Simenstad 2015). Finally, does the sediment carbon sink of a sparsely vegetated, restoring salt marsh differ from that of a reference (historical) marsh, and if so, how? Although no studies to date have compared the provenance of carbon in restoring vs. historically unaltered (reference) marshes, several studies have focused on carbon sources and their relative contributions to blue carbon sediment sinks in mangroves (Gonneea et al. 2004; Xue et al. 2009; Prasad et al. 2017), seagrass meadows (Greiner et al. 2016; Reef et al. 2017; Oreska et al. 2018), and salt marshes (Bull et al. 1999; Gao et al. 2016; Santos et al. 2018). Two of these studies were carried out in the Virginia Coast Reserve along the southern Delmarva peninsula, which contains $1700+$ ha of restored seagrass habitat (Greiner et al. 2016; Oreska et al. 2018). In their paper, Greiner et al. (2016) state that the relative contribution of seagrass-derived carbon to sediment carbon pools in unvegetated sites was related to the proximity and shoot density of seagrasses. Oreska et al. (2018) also working in the Virginia Coast Reserve found that $>70 \%$ of the carbon in two unvegetated sites came from the neighboring seagrass meadow and not the Spartina alterniflora marsh, which was further afield. Similar studies are needed in tidal marshes to better understand how carbon source abundance and proximity factor into the composition of the sediment carbon sink.

The overall goal of this study was to address the above questions by comparing the sediment carbon sink of a recently restored, subsided, and sparsely vegetated salt marsh to a nearby, historically unaltered salt marsh in the Nisqually River Delta (NRD) of southern Puget Sound, Washington, USA. Our specific objectives were to determine (1) the major carbon sources and their relative contributions to the sediment carbon sinks in the restoring and reference marshes and (2) whether or not the restoring and reference marshes in the study differ in the compositions of their carbon sinks. We first used $\delta^{13} \mathrm{C}, \delta^{15} \mathrm{~N}$, and $\delta^{34} \mathrm{~S}$ values to determine differences in the isotopic signatures of the restoring and reference marsh sediments. Then we used $\delta^{13} \mathrm{C}$ and $\delta^{15} \mathrm{~N}$ values of marsh sediments and major potential carbon sources in a Bayesian stable isotope mixing model (SIMM) to determine the relative contributions of organic carbon sources to the sediment carbon sink of each marsh.

We conducted this research in the NRD, site of one of the largest and highly studied estuarine restoration projects to date in the Pacific Northwest (David et al. 2014; Ellings et al. 2016; Ballanti et al. 2017; Woo et al. 2018) because it provided a rare opportunity to compare carbon accumulation processes in a restoring, subsided, largely unvegetated salt marsh to an adjacent fully vegetated, historically unaltered, reference salt marsh. At the NRD, previous research has shown that the restoring, subsided, and sparsely vegetated salt marsh (Six Gill Slough, hereafter the Restoring Marsh), accreted sediment at approximately twice the rate of the nearby, historical reference salt marsh (Animal Slough, hereafter the Reference Marsh) since restoration in 2009 (Restoring Marsh: $0.79 \pm 0.29$ (SD) cm year $^{-1}$; Reference Marsh: $0.41 \pm 0.16 \mathrm{~cm}_{\text {year }}{ }^{-1}$; Drexler et al. 2019). In addition, vertical accretion was found to consist of $55 \%$ inorganic matter at the Reference Marsh in contrast to 95\% inorganic matter at the Restoring Marsh (Drexler et al. 2019). Such data suggest that a greater amount of allochthonous material is being deposited in the Restoring Marsh vs. the Reference Marsh. For this reason, we had two main hypotheses about the carbon sinks at each site: (1) the sediment carbon sink at the Reference Marsh is comprised of a greater percentage of autochthonous carbon than at the Restoring Marsh and (2) the carbon sink at the Restoring Marsh acts as a broad receiving ground due to its subsided and sparsely vegetated state, storing a greater relative proportion of different carbon sources than the Reference Marsh.

\section{Methods}

\section{Study Site}

The NRD is located at the mouth of the Nisqually River in southern Puget Sound near Olympia, Washington, USA ( $47^{\circ}$ 
$4^{\prime} 47.99^{\prime \prime} \mathrm{N}, 122^{\circ} 42^{\prime} 0^{\prime \prime} \mathrm{W}$ ) (Fig. 1). Tides range from mean higher high water at $4.11 \mathrm{~m}$ to mean lower low water at $1.07 \mathrm{~m}$ (USFWS 2005). Climate in the region is predominantly wet and temperate. Annual precipitation is $\sim 1000 \mathrm{~mm}$ (Curran et al. 2016). The Nisqually River originates at the base of Mount Rainier and carries $\sim 1,200,000$ metric tons of sediment each year; however, only $\sim 99,000$ metric tons of this sediment load (8\%) reaches Puget Sound due to upstream dams (Curran et al. 2016). The mean discharge of the Nisqually River ranges from 28 to 57 cubic meters per second (cms) during low seasonal flows while peak flows reach $368 \mathrm{cms}$ (Curran et al. 2016). Water years with high rates of discharge and flooding deliver the most sediment from the Nisqually River to the delta (USFWS 2005; Curran et al. 2016).

The heart of the NRD was drained and diked for agriculture in the 1880s. This change in land use led to land-surface subsidence due to microbial oxidation of soils and compaction from grazing animals and agricultural practices (Frenkel and Morlan 1991; Portnoy and Giblin 1997). In 1974, the Billy Frank Jr. Nisqually National Wildlife Refuge (NISQ) was established at the mouth of the Nisqually River and the diked agricultural areas passively transitioned from fallow fields to a rain-fed, freshwater marsh (USFWS 2005). The freshwater marsh was increasingly invaded by invasive reed canary grass (Phalaris arundinacea), and over time the aging dike system required greater maintenance and repairs. Thus, NISQ partnered with the Nisqually Indian Tribe to restore the NRD to benefit waterbirds, fish, and wildlife (USFWS 2005), including the federally threatened Nisqually Fall Chinook salmon (Oncorhynchus tshawytscha) (Shared Strategy for Puget Sound 2007; David et al. 2014; Ellings et al. 2016).

Restoration of the NRD began in phases starting with a pilot project in 1996 (4 ha), phase I in 2002 (13 ha), and phase

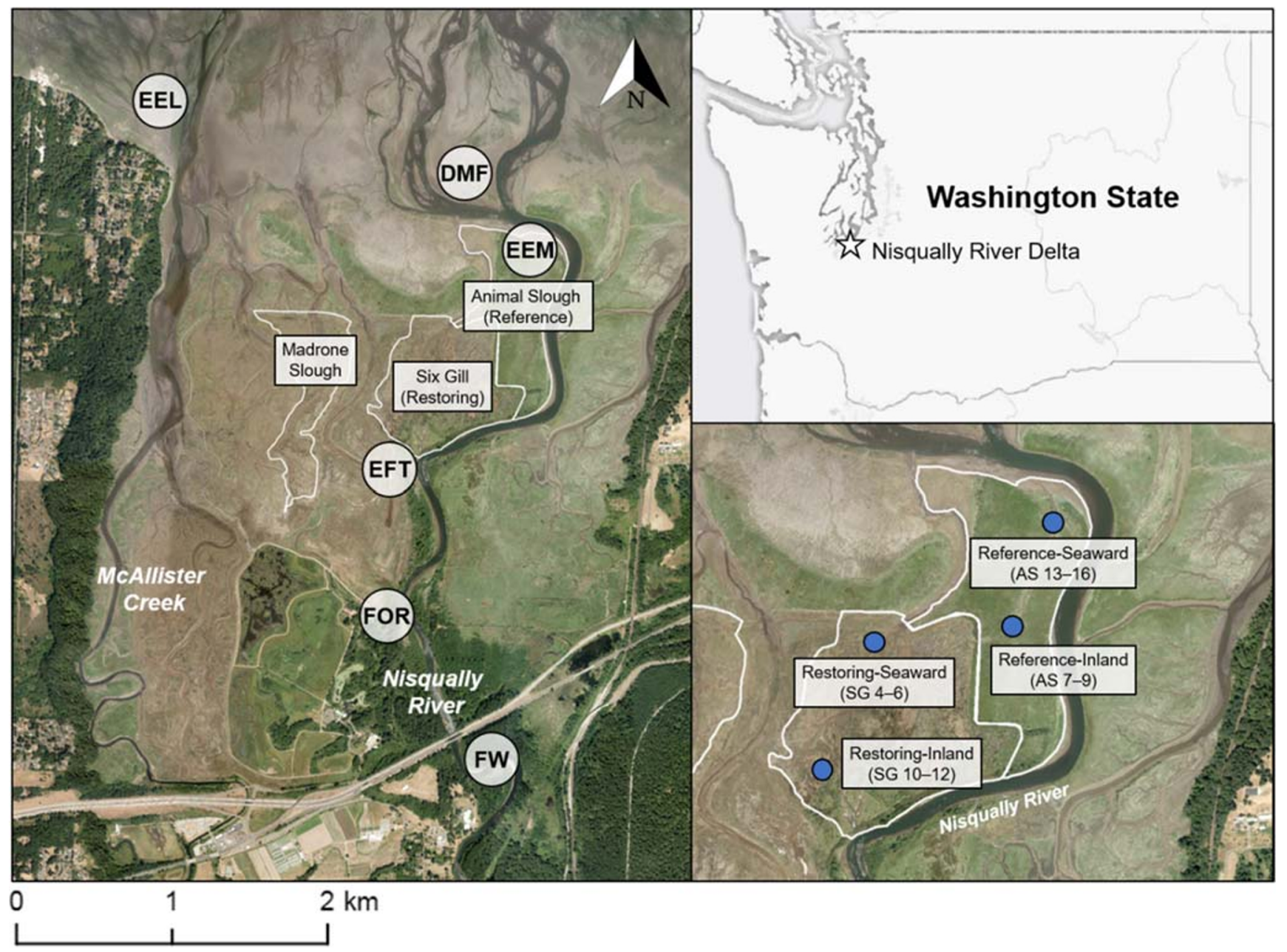

Fig. 1 Map of the Nisqually River Delta (NRD) in southern Puget Sound, Washington, USA. Parcels of interest to this study, Madrone Slough, Six Gill Slough (Restoring Marsh), and Animal Slough (Reference Marsh) are outlined with a white line. Sediment cores (inset, lower right) were collected in 2015 and 2017 at the Reference Marsh at Inland and Seaward locations, respectively, and in 2015 at both Restoring Marsh locations.
Organic carbon sources were collected in 2015 in six habitat types: freshwater (FW), tidal forested (FOR), brackish transitional marsh (EFT), emergent salt marsh (EEM), delta mudflat (DMF), and eelgrass (EEM). Benthic diatoms were collected in 2011 at Madrone Slough and the Reference Marsh 
II in 2006 (41 ha). The restoration culminated in phase III in November 2009 when the removal of a century-old dike system returned 308 ha of marsh to tidal flow and restored a total of 365 ha of estuarine habitat (Ellings et al. 2016). In addition to its emergent tidal marshes, the NRD is comprised of multiple habitat types including freshwater tidal forests, intertidal mudflats, and eelgrass beds (Zostera marina) (Davis et al. 2018; Woo et al. 2019). Here, we focus on the polyhaline or "brackish" marsh zone in the NRD, but for simplicity will refer to both marshes in this study as salt marshes. The marsh plain of the Restoring Marsh is approximately 20\% vegetated, consisting of patches of Salicornia pacifica (pickleweed) and Spergularia spp. (sandspurry) in areas of higher elevation (Belleveau et al. 2015). At last measurement, the elevation of the phase III area restored in 2009, which includes the Restoring Marsh, was $\sim 0.5$ to $0.88 \mathrm{~m}$ lower in elevation than other marsh areas of the NRD (Belleveau et al. 2015). The Reference Marsh (Animal Slough) is a small reach within an intact, relatively pristine polyhaline marsh (David et al. 2014), which is fully vegetated and dominated by Carex lyngbyei (Lyngbye's sedge), Distichlis spicata (saltgrass), and Potentilla anserina (silverweed) (Burg et al. 1980; Belleveau et al. 2015).

\section{Data Collection}

\section{Sediment Core Collection and Analysis}

Sediment cores were collected in both marshes with a Hargis corer (Hargis and Twilley 1994) along transects perpendicular to sloughs at two locations: (1) in close proximity to Puget Sound (Seaward) and (2) $\sim 1 \mathrm{~km}$ upstream of Puget Sound (Inland) in order to characterize marsh sediments along the salinity gradient (Fig. 1). This coring scheme allowed for adequate replication at each location and the comparison of inland and seaward processes at both marshes. Depth of coring was related to ease of collection. Cores in the Restoring Marsh were collected to $\sim 30 \mathrm{~cm}$ in depth; however, only the surface sections deposited since restoration were used for the stable isotope analysis described below (Online Resources 1: Table S1). Cores in the Reference Marsh were collected to $50 \mathrm{~cm}$ in depth. Same as the Restoring Marsh cores, only the surface sections of each core were used for the stable isotope analysis (Table S1); however, deeper sections were used to compare pre- and post-restoration differences in stable isotope signatures for evidence of diagenesis, as described below. Cores SG4-SG6, SG10-SG12 (Restoring Marsh), and AS7AS9 (Reference Marsh) were collected in April 2015 and cores AS14-AS16 (Reference Marsh) were collected in May 2017 (Fig. 1). After collection, all cores were shipped overnight to USGS laboratories in Sacramento, California, for further processing. In the laboratory, sediment cores were sectioned into $2 \mathrm{~cm}$ sections, dried, and then ground to pass through a $2 \mathrm{~mm}$ sieve.

Sediment core sections from the Restoring and Reference Marshes were analyzed at the U.S. Geological Survey in Menlo Park, California, for ${ }^{137} \mathrm{Cs},{ }^{210} \mathrm{~Pb}$, and ${ }^{226} \mathrm{Ra}$. Activities of total ${ }^{210} \mathrm{~Pb},{ }^{226} \mathrm{Ra}$, and ${ }^{137} \mathrm{Cs}$ were measured simultaneously by gamma spectrometry as described in Drexler et al. (2017). Subsamples radioisotopes were measured using a high-resolution intrinsic germanium well detector gamma spectrometer. Samples were placed in the detector borehole or well, which provides near $4 \pi$ counting geometry. Sediment samples were sealed in $7 \mathrm{~mL}$ polyethylene scintillation vials. The supported ${ }^{210} \mathrm{~Pb}$ activity, defined by the ${ }^{226} \mathrm{Ra}$ activity, was determined on each interval from the $352 \mathrm{keV}$ and $609 \mathrm{keV}$ gamma emission lines of the short-lived daughters ${ }^{214} \mathrm{~Pb}$ and ${ }^{214} \mathrm{Bi}$ daughters of ${ }^{226} \mathrm{Ra}$, respectively. The ${ }^{137} \mathrm{Cs}$ activity was determined from the $661.5 \mathrm{keV}$ gamma emission line. Self-absorption of the ${ }^{210} \mathrm{~Pb} 46 \mathrm{keV}$ gamma emission line was accounted for using an attenuation factor calculated from an empirical relationship between self-absorption and bulk density developed for this geometry based on the method of Cutshall et al. (1983). Additional information regarding standards, random counting errors, and quality assurance/quality control can be found in Drexler et al. (2017).

Marsh cores were dated using ${ }^{210} \mathrm{~Pb}$ and ${ }^{137} \mathrm{Cs}$; however, due to low activities of ${ }^{137} \mathrm{Cs}$ on the west coast of the US and the mobility of ${ }^{137} \mathrm{Cs}$ in some of the cores (Drexler et al. 2018), we used ${ }^{210} \mathrm{~Pb}$ exclusively for dating. The constant rate of supply approach (Appleby and Oldfield 1978; Appleby and Oldfield 1983) was used to establish the age-depth relationship of each core. Uncertainties in ${ }^{210} \mathrm{~Pb}$ dating were calculated following Van Metre and Fuller (2009). Further details on dating cores and estimating carbon accumulation rates for each study location can be found in Drexler et al. (2019).

Core sections (Online Resource 1: Tables S1 and S2) were sub-sampled for stable isotope analysis in the following manner. Reference Marsh core sections were taken from both the pre- (2000-2009) and post-restoration (2010-2017) periods, but only the post-restoration sections were used in the Bayesian SIMM analysis. Restoring Marsh sections were taken only from the post-restoration period, because farming practices and land-surface subsidence disturbed the prerestoration sediment stratigraphy, precluding temporal analysis of sediment characteristics. Each 2-cm core section used in the stable isotope analysis together with its mid-section date is provided in Online Resource 1: Table S1. Approximately $2 \mathrm{~g}$ of dried, ground sediment from each section was placed in a whirlpak bag and stored until analysis.

\section{Organic Carbon Sources}

We collected vascular plants, wrack, macroalgae, benthic microalgae, and particulate organic matter (POM) from six 
estuarine habitats positioned along a salinity gradient (freshwater, tidal forested, brackish transitional marsh, emergent salt marsh, delta mudflat, and eelgrass) for inclusion as potential carbon sources in the Bayesian SIMM (Fig. 1).

Between April 22 and May 28, 2015, we collected three replicate above- and belowground samples of vascular plants in each habitat type by pulling an individual stalk by the root or by trimming a single branch if the plant was too large to uproot. We sampled salmonberry (Rubus spectabilis Pursh), Himalayan blackberry (Rubus armeniacus Focke), willow (Salix spp.), maple (Acer macrophyllum Pursh), and stinging nettle (Urtica dioica L.) in the freshwater and forested habitats; broad-leaf cattail (Typha latifolia L.), needle spikerush (Eleocharis acicularis L.), and Lyngbye's sedge (Carex lyngbyei Hornem) in the transitional marsh; Lyngbye's sedge, saltgrass (Distichlis spicata L., the only C4 plant included in the study), and pickleweed (Sarcocornia pacifica Standl.) in the emergent salt marsh; and common eelgrass (Zostera marina L.) in the subtidal eelgrass habitat. No rooted vascular plant species were collected in the delta mudflat because none were present. We triple washed each sample in a bin of distilled water to remove invertebrates and debris. Aboveground and belowground biomass were processed separately. For each sample, $\sim 10 \mathrm{~g}$ of plant matter from each stalk was placed in a whirlpak bag and stored at $5{ }^{\circ} \mathrm{C}$ for subsequent analysis.

We collected macroalgal samples in the emergent salt marsh, delta mudflat, and eelgrass habitats. Samples were collected between May 6 and May 27 of 2015. We collected two species of algae: brown algae (Fucus distichus) was sampled in the emergent marsh and sea lettuce (Ulva lactuca) was sampled at the mudflat and eelgrass sites. Six replicate samples were collected by hand at each site and stored in plastic bags on ice. Upon return to the lab, we triple washed each sample separately to remove invertebrates and debris. Samples were clipped to $\sim 30 \mathrm{~g}$ wet material and stored in whirlpak bags at $5{ }^{\circ} \mathrm{C}$.

We sampled for benthic microalgae (i.e., diatoms) by scraping approximately $40 \mathrm{~g}$ of biofilm from the top $1-2 \mathrm{~mm}$ of the marsh surface. Biofilm was stored in a plastic bag, wrapped in aluminum foil to keep dark, and refrigerated at $5{ }^{\circ} \mathrm{C}$. Samples were shipped overnight to the USGS San Francisco Estuary Invertebrate Ecology Lab on the day of collection. To extract diatoms, sediment was spread onto 1-cm-deep plastic pans. The sediment surface was covered with a nylon screen (Nytex $63 \mu \mathrm{m}$ mesh), pre-combusted glass wool fibers were placed on top, and the glass wool was sprayed with filtered $(0.2 \mu \mathrm{m}$ mesh) saltwater to allow for the vertical movement of diatoms onto the glass wool fibers (Couch 1989). After $24 \mathrm{~h}$ under laboratory lights, the glass wool fibers were collected, frozen, and shipped to the Colorado Plateau Stable Isotope Laboratory (CPSIL) for stable isotope analyses. In April and May 2015, we collected three replicate samples from the transition, emergent salt marsh, and delta mudflat habitats; however, we were unable to extract sufficient amounts of diatoms from these samples for analysis. Instead, we used samples that were collected at the Reference Marsh and Madrone Slough in June 2011 using the same procedure. Madrone Slough is a restoring tidal marsh less than $0.5 \mathrm{~km}$ from the Restoring Marsh that is very similar in mean elevation (Restoring Marsh elevation $=2.05 \pm 0.11 \mathrm{~m}$ NAVD88, Madrone $=1.98 \pm 0.12 \mathrm{~m}$ NAVD88) and vegetated cover $(<$ $20 \%$ cover at both sites).

To sample for POM, we used 5-gal carboys to collect water samples in the water column adjacent to each of the six habitat types. We sampled on May 6-8, May 26-28, and June 4-5, 2015 for a total of eight replicate samples per habitat. Upon return to the lab, we filtered each carboy of water through a $100 \mu \mathrm{m}$ sieve to remove zooplankton. We then ran the sample through a second, $20 \mu \mathrm{m}$ sieve to collect POM. The contents of the $20 \mu \mathrm{m}$ sieve were rinsed through a vacuum filtration system and collected using two $5 \mu \mathrm{m}$ combusted glass fiber filters: one for stable isotope analysis and one for fluorometry. Each sample was stored in a whirlpak bag, covered in aluminum foil, and frozen prior to shipment to the lab.

\section{Stable Isotope Analysis}

All biological samples were shipped on dry ice and all sediment samples were shipped on wet ice to CPSIL for elemental (\% organic $\mathrm{C}, \%$ total $\mathrm{C}, \%$ total $\mathrm{N}$, and $\%$ total $\mathrm{S}$ by weight) and ${ }^{13} \mathrm{C},{ }^{15} \mathrm{~N}$, and ${ }^{34} \mathrm{~S}$ analysis. Carbon and nitrogen samples were run on a Thermo-Electron Delta V Advantage isotope ratio mass spectrometer (IRMS) configured through a Finnigan CONFLO III for automated continuous-flow analysis of $\delta^{15} \mathrm{~N}$ and $\delta^{13} \mathrm{C}$, using a Carlo Erba NC2100 elemental analyzer for combustion and separation of carbon and nitrogen. For sulfur samples, a DELTA plus Advantage IRMS was configured through a CONFLO III for automated continuousflow analysis of $\delta^{34} \mathrm{~S}$ using a Costech ECS4010 Elemental Analyzer. NIST 1547 (peach leaves) was used as the internal laboratory working standard for C and N, and NIST 1577 (bovine liver) was the internal standard for S. Peach leaves and bovine liver were interspersed throughout each run $(\sim$ every ten samples) to check for drift and were included at the end of each run as a weight series to check on linearity. The long-term analytical precision was $\pm 0.04 \%$ ofor $\delta^{13} \mathrm{C}, \pm$ $0.07 \%$ for $\delta^{15} \mathrm{~N}$, and $\pm 0.06 \%$ for $\delta^{34} \mathrm{~S}$. Additional information on instrumentation and quality control/quality assurance procedures can be found at http://www.isotope.nau.edu/index. html.

Stable isotopes of carbon, nitrogen, and sulfur are expressed in standard delta notation:

$\delta X=1000 \times\left(\frac{R_{\text {sample }}}{R_{\text {standard }}}-1\right)$ 
where $X=\delta^{13} \mathrm{C}, \delta^{15} \mathrm{~N}$, or $\delta^{34} \mathrm{~S}$ and $R$ is the ratio of heavy and light isotopes in a sample $\left({ }^{13} \mathrm{C}:{ }^{12} \mathrm{C},{ }^{15} \mathrm{~N}:{ }^{14} \mathrm{~N}\right.$, and $\left.{ }^{34} \mathrm{~S}:{ }^{32} \mathrm{~S}\right)$. Stable isotope ratios are expressed as parts per mil (\%o) differences relative to international standards: Pee Dee belemnite for $\delta^{13} \mathrm{C}$, atmospheric nitrogen for $\delta^{15} \mathrm{~N}$, and Vienna-Canyon Diablo troilite for $\delta^{34} \mathrm{~S}$.

\section{Statistical Analysis}

We used a permutational multivariate analysis of variance (PERMANOVA) to test among-group differences in the $\delta^{13} \mathrm{C}$, $\delta^{15} \mathrm{~N}$, and $\delta^{34} \mathrm{~S}$ composition of marsh sediments at inland and seaward locations in the Restoring Marsh and Reference Marsh. All PERMANOVA analyses were run in R using the "vegan" package. We tested a full model that included an interaction effect between site (Reference, Restoring) and sampling location (Seaward, Inland). A site-specific PERMANOVA was used to conduct post hoc pairwise comparisons between Inland and Seaward locations within sites. Prior to running each PERMANOVA, we tested for the assumption of similar multivariate dispersion using the "betadisper" function, where a $p$ value $>0.05$ indicated that the spread among the test groups was not significant and the assumption was not violated. For our response matrix, we used a Euclidean distance matrix that included all three isotopes. The model was run for 1000 permutations, where a significance cutoff of $p<0.05$ verified amongsite and among-location differences in isotopic signatures.

We used a Bayesian SIMM (Phillips and Gregg 2003; Parnell et al. 2010) to derive posterior estimates of the organic carbon sources contributing to NRD marsh sediments. In contrast to earlier approaches, the Bayesian SIMM used in this paper can accommodate multiple source groupings as long as those groups are isolated in isotopic space and the mixtures are confined within the isotopic mixing polygon (Moore and Semmens 2008; Parnell et al. 2010). Nine source groupings were established using a hierarchical clustering algorithm with Ward's minimum variance method (Murtagh and Legendre 2014). We applied this procedure on a Euclidean distance matrix of $\delta^{13} \mathrm{C}, \delta^{15} \mathrm{~N}$, and $\delta^{34} \mathrm{~S}$ to create groups that were distinct in isotopic space and biologically meaningful for the NRD. The clustering procedure was performed separately for the vascular plant, macroalgae, benthic microalgae, and POM organic carbon sources. Although it is often comprised of multiple carbon sources, we included POM in our analysis because chlorophyll-a (5.66$19.68 \mu \mathrm{g} / \mathrm{L})$ and pheophytin $(5.00-15.84 \mu \mathrm{g} / \mathrm{L})$ measurements indicated that NRD POM contains substantial amounts of phytoplankton - a biologically unique carbon source for this study (USGS, unpublished data). Furthermore, the C:N ratios of POM ranged from 8 to 12 , demonstrating that phytoplankton is likely an important contributor to NRD POM, even if it is not necessarily the dominant constituent (Kendall et al. 2001).

We used the R program "IsotopeR" (Hopkins and Ferguson 2015) to run the Bayesian SIMM on four mixture groups:
Reference-Inland, Reference-Seaward, Restoring-Inland, and Restoring-Seaward. Only $\delta^{13} \mathrm{C}$ and $\delta^{15} \mathrm{~N}$ were used in the mixing model because we did not have enough biomass for $\delta^{34} \mathrm{~S}$ measurements of the benthic microalgae and POM samples. The IsotopeR package allows for inclusion of measurement and discrimination errors. We included a measurement error of $0.04 \%$ of $\delta^{13} \mathrm{C}$ and $0.07 \%$ for $\delta^{15} \mathrm{~N}$ based on the precision determined for the standards used by CPSIL. We included a discrimination factor of $0.17 \%$ for $\delta^{13} \mathrm{C}$ and $0.24 \%$ for $\delta^{15} \mathrm{~N}$, which is the standard deviation of the change in $\delta^{13} \mathrm{C}$ and $\delta^{15} \mathrm{~N}$ core section values since the time of restoration.

In addition to these sources of error, we also considered the impact of diagenesis on marsh sediments, which constitutes the sum of all natural processes, largely chemical, resulting in changes to sediments after their deposition. In organic matter, diagenesis, which is mainly controlled by microbial decomposition, results in shifts in stable isotope signatures through time (Freudenthal et al. 2001; Lehmann et al. 2002). Previous work in blue carbon ecosystems has shown that diagenesis of organic matter can cause changes of $1-2 \%$ over periods of $1-$ 3 months, with $\delta^{15} \mathrm{~N}$ changing more than $\delta^{13} \mathrm{C}$ (Greiner et al. 2016; Jankowska et al. 2016); however, the effect could be greater depending on the sources of carbon and the time period over which it occurs. We could not find literature values for diagenesis on the timescale of our study ( $~ 6$ years), nor could we find any approaches for determining uncertainty in stable isotope values of core samples, so we conducted a sensitivity analysis in IsotopeR. Although our Bayesian SIMM provides posterior probability distributions for mixtures (core samples), we wanted to perform an additional analysis to see how diagenetic changes in stable isotope signatures of core samples could potentially impact the analysis. We chose the following three scenarios to explore the sensitivity of the SIMM to the mean and full range of stable isotope values of sediments deposited since restoration: (S1) mean change in $\delta^{13} \mathrm{C}$ and $\delta^{15} \mathrm{~N}$ values of core sediments $\left(\Delta \delta^{13} \mathrm{C}=0.29 \%, \Delta \delta^{15} \mathrm{~N}=-\right.$ $0.11 \%$ ), (S2) maximum positive change in $\delta^{13} \mathrm{C}$ and $\delta^{15} \mathrm{~N}$ values $\left(\Delta \delta^{13} \mathrm{C}=0.53 \%, \Delta \delta^{15} \mathrm{~N}=0.13 \%\right.$ ) , and (S3) maximum negative change in $\delta^{13} \mathrm{C}$ and $\delta^{15} \mathrm{~N}$ values $\left(\Delta \delta^{13} \mathrm{C}=\right.$ $0.00 \%, \Delta \delta^{15} \mathrm{~N}=-0.48 \%$ ). Output from the sensitivity analysis was compared to output from the original model run to determine how diagenesis and within-sample variability might have affected posterior estimates of source contributions. We also tested for evidence of diagenesis by using a separate PERMANOVA procedure to compare the $\delta^{13} \mathrm{C}, \delta^{15} \mathrm{~N}$, and $\delta^{34} \mathrm{~S}$ signatures of core sections from the Reference Marsh before restoration (2000-2009) to core sections from the post-restoration period (2010-2017).

\section{Carbon Accumulation by Source}

The relative contributions of carbon sources determined by the Bayesian SIMM analysis for the original model were 
multiplied by the mean carbon accumulation rates at the Reference Marsh and Restoring Marsh to estimate the carbon accumulation rates of individual source components at both sites. Mean carbon accumulation rates in sediments $\sim 6$ years after restoration at the Restoring Marsh and Reference Marsh were approximately $164 \pm 54$ and $134 \pm 19 \mathrm{~g} \mathrm{C} \mathrm{m}^{-2}$ year $^{-1}$, respectively (Drexler et al. 2019).

\section{Results}

\section{Organic Carbon Sources}

Based on the hierarchical clustering analysis, we separated organic carbon sources into nine groups for the Bayesian analysis (Fig. 2, Table 1). The assumptions of the Bayesian SIMM were met as each source grouping was isolated in isotopic space and the mixtures were confined within the isotopic mixing polygon (Fig. 2). POM was split into Riverine POM (freshwater, forested, and transitional), Marsh POM (emergent marsh), and Delta POM (mudflat and eelgrass). Macroalgal isotope signatures indicated two distinct groups based on species $(F$. distichus and $U$. lactuca). Because $F$. distichus had isotopic signatures that were highly similar to Delta POM and were likely to confound posterior estimates for the Bayesian SIMM, we omitted this source to limit model error. Diatom signatures were distinct between the Reference Marsh and Restoring Marsh, likely because of small differences in salinity, species assemblages, and the extracellular polymeric substances particular species excrete, which can alter isotopic signatures (Cloern et al. 2002; Hubas et al. 2018). Vascular plants exhibited the greatest amount of variability in $\delta^{13} \mathrm{C}$,

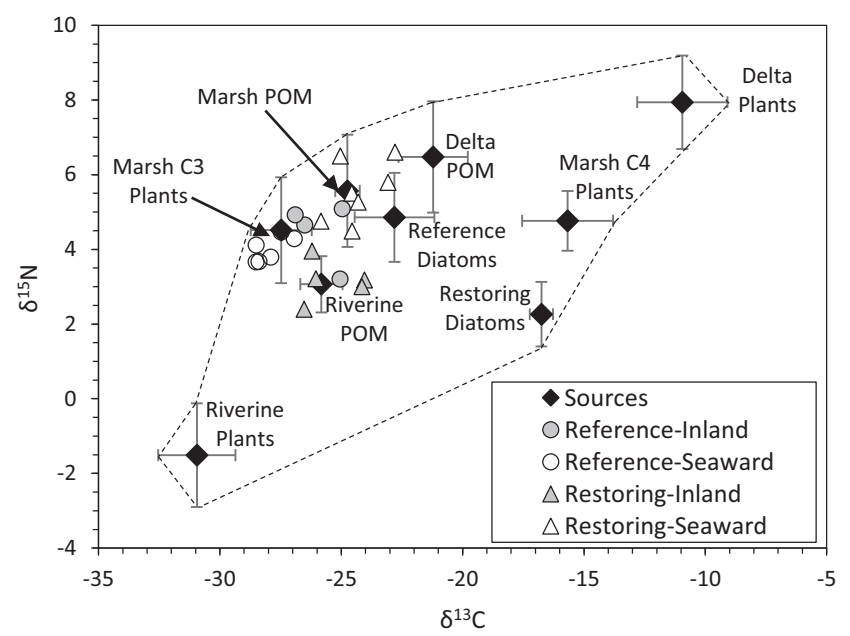

Fig. 2 Biplot of $\delta^{13} \mathrm{C}$ and $\delta^{15} \mathrm{~N}$ values for mixtures (Restoring Marsh and Reference Marsh core sections) and mean $\delta^{13} \mathrm{C}$ and $\delta^{15} \mathrm{~N}$ values of organic carbon sources (error bars $=\mathrm{SD}$ ) in the NRD. The dashed lines encompass the isotopic mixing space of the organic carbon sources sampled in the study $\delta^{15} \mathrm{~N}$, and $\delta^{34} \mathrm{~S}$ among species and habitats. We separated vascular plants into four sources: (1) Riverine Plants including above and belowground biomass from the freshwater and tidal forested habitats, (2) Marsh C3 Plants including above and belowground biomass from the transitional and emergent marsh habitats, (3) Marsh C4 Plants consisting only of $D$. spicata from the emergent marsh habitat, and (4) Delta Plants consisting of Z. marina and $U$. lactuca, which had overlapping $\delta^{13} \mathrm{C}, \delta^{15} \mathrm{~N}$, and $\delta^{34} \mathrm{~S}$ signatures.

Of the organic carbon source groupings, Riverine Plants had the most depleted $\delta^{13} \mathrm{C}$ and $\delta^{15} \mathrm{~N}$ values and Delta Plants had the most enriched $\delta^{13} \mathrm{C}$ and $\delta^{15} \mathrm{~N}$ values (Fig. 2, Table 1). $\delta^{13} \mathrm{C}$ and $\delta^{15} \mathrm{~N}$ increased along the salinity gradient from freshwater to delta sources. Although all vascular plants had similar $\delta^{15} \mathrm{~N}$ values, the $\delta^{13} \mathrm{C}$ values of the $\mathrm{C} 4$ plant $D$. spicata were greater due to the distinctly enriched $\delta^{13} \mathrm{C}$ signatures of C4 relative to C3 plants (Bender 1971; O'Leary 1988).

\section{Isotopic Signatures of Restoring and Historic Sediments}

Among-site differences accounted for $\sim 86 \%$ of the variation in $\delta^{13} \mathrm{C}, \delta^{15} \mathrm{~N}$, and $\delta^{34} \mathrm{~S}$ signatures among sediment cores, and there was a significant interaction effect with sampling location (Table 2). The Reference Marsh was less enriched in $\delta^{13} \mathrm{C}$ than the Restoring Marsh (Reference $=-27.11 \pm 1.32 \%$, Restoring $=-24.76 \pm 1.21 \%$ ) and more enriched in $\delta^{34} \mathrm{~S}$ (Reference $=11.61 \pm 3.78 \%$, Restoring $=-12.77 \pm 5.62 \%$; Fig. 3, Table S1, Table S2). Among-site differences in $\delta^{15} \mathrm{~N}$ were negligible (Reference $=4.19 \pm 0.61 \%$, Restoring $=4.55$ $\pm 1.42 \%$; Fig. 3). At the Reference Marsh, stable isotope signatures did not vary between the Seaward and Inland sampling locations (pairwise post hoc comparison: $F_{1,8}=0.76$, $p=0.432)$. In the Restoring Marsh, they differed $\left(F_{1,10}=\right.$ 15.67, $p=0.002)$, especially with respect to $\delta^{15} \mathrm{~N}$ $($ Seaward $=5.56 \pm 0.81 \%$, Inland $=3.15 \pm 0.56 \% \circ)$ and $\delta^{34} \mathrm{~S}$ (Seaward $=-16.35 \pm 2.45 \%$ o, Inland $=-7.76 \pm 4.91 \%$ o). The organic C:total $\mathrm{N}$ ratios at the Reference Marsh were greater than those at the Restoring Marsh (Reference $=15.83 \pm 1.55$; Restoring $=10.79 \pm 1.92$; Fig. 3.)

\section{Allochthonous vs. Autochthonous Contributions to Restoring vs. Historic Sediments}

The contributions of allochthonous vs. autochthonous organic carbon sources to marsh sediments strongly differed between the Restoring Marsh and the Reference Marsh (Table 3; Online Resource 1: Table S3). At the Reference Marsh, autochthonous Marsh C3 Plants were the top contributor of carbon to both the inland (87\%) and seaward locations (93\%). We assumed that all of the carbon from Marsh C3 Plants and Marsh POM was produced in situ at the Reference Marsh due 
Table 1 Posterior probability distribution of sources (means, SDs, and credible intervals shown as quantiles) for the Bayesian SIMM

\begin{tabular}{|c|c|c|c|c|c|c|c|c|}
\hline Isotope & Sources & Mean isotope value & $\mathrm{SD}$ & $2.5 \%$ quantile & $25 \%$ quantile & $50 \%$ quantile & $75 \%$ quantile & $97.5 \%$ quantile \\
\hline \multirow[t]{9}{*}{$\delta^{13} \mathrm{C}:$} & POM Riverine & -25.80 & 0.18 & -26.17 & -25.92 & -25.80 & -25.68 & -25.45 \\
\hline & POM Marsh & -24.77 & 0.22 & -25.23 & -24.90 & -24.76 & -24.64 & -24.32 \\
\hline & POM Delta & -21.20 & 0.39 & -21.97 & -21.45 & -21.20 & -20.95 & -20.43 \\
\hline & Diatoms Reference & -22.77 & 0.48 & -23.70 & -23.07 & -22.79 & -22.46 & -21.78 \\
\hline & Diatoms Restored & -16.75 & 0.14 & -17.03 & -16.84 & -16.75 & -16.66 & -16.47 \\
\hline & Plants Riverine & -30.94 & 0.19 & -31.32 & -31.07 & -30.94 & -30.81 & -30.56 \\
\hline & Marsh C3 Plants & -27.59 & 0.22 & -28.04 & -27.73 & -27.58 & -27.43 & -27.18 \\
\hline & Marsh C4 Plants & -15.61 & 0.59 & -16.79 & -15.98 & -15.63 & -15.24 & -14.43 \\
\hline & Delta Plants & -10.94 & 0.51 & -11.92 & -11.27 & -10.94 & -10.60 & -9.95 \\
\hline \multirow[t]{9}{*}{$\delta^{15} \mathrm{~N}:$} & POM Riverine & 3.08 & 0.16 & 2.77 & 2.98 & 3.08 & 3.19 & 3.39 \\
\hline & POM Marsh & 5.63 & 0.56 & 4.61 & 5.27 & 5.59 & 5.96 & 6.85 \\
\hline & POM Delta & 6.50 & 0.41 & 5.72 & 6.25 & 6.51 & 6.76 & 7.29 \\
\hline & Diatoms Reference & 4.90 & 0.35 & 4.20 & 4.67 & 4.90 & 5.12 & 5.61 \\
\hline & Diatoms Restored & 2.27 & 0.26 & 1.75 & 2.10 & 2.26 & 2.43 & 2.79 \\
\hline & Plants Riverine & -1.51 & 0.17 & -1.83 & -1.62 & -1.51 & -1.40 & -1.18 \\
\hline & Marsh C3 Plants & 4.46 & 0.23 & 4.02 & 4.30 & 4.45 & 4.60 & 4.92 \\
\hline & Marsh C4 Plants & 4.78 & 0.26 & 4.29 & 4.61 & 4.77 & 4.94 & 5.32 \\
\hline & Delta Plants & 7.93 & 0.34 & 7.26 & 7.71 & 7.93 & 8.15 & 8.61 \\
\hline
\end{tabular}

to the fact that it was almost entirely vegetated, except for channels, at the time of the study. In order to estimate the allochthonous vs. autochthonous sources of carbon in the Restoring Marsh, we first had to make an assumption about the origin of the autochthonous contributions, which included Marsh C3 Plants and Marsh POM but not Marsh C4 Plants. Due to the fact that the Restoring Marsh was $~ 20 \%$ vegetated at the time of the study, we assumed that a full $\sim 20 \%$ of the Marsh C3 Plant and Marsh POM contributions to the sediments were provided by in situ production. In so doing, we assumed that the remaining $\sim 80 \%$ of these two sources were allochthonous, having washed in from the Reference Marsh. Although other interpretations may be possible, we arrived at these assumptions due to the specific characteristics of our study sites. Following this methodology, allochthonous contributions at Restoring-Inland represented $\sim 91 \%$ of carbon sources, while allochthonous contributions at RestoringSeaward represented $\sim 87 \%$ (Table 3 ). At Restoring-Inland, about half the organic carbon in the sediment sink originated from Nisqually River sources (Fig. 4, Table 3). At RestoringSeaward, riverine sources comprised only about $5 \%$ of the allochthonous materials (Fig. 4).
Table 2 PERMANOVA partitioning and results for analysis I: Reference Marsh and Restoring Marsh sediments dated to the postrestoration period (2010-2017) and analysis II: Reference Marsh sediments dated to the pre- (2000-2009) and post-restoration periods. Site refers to Restoring Marsh and Reference Marsh and Location refers to Inland or Seaward

\begin{tabular}{|c|c|c|c|c|}
\hline Source & Df & Sum of squares & Pseudo $F$ & $R^{2}(p$ value $)$ \\
\hline \multicolumn{5}{|l|}{ Analysis I } \\
\hline Site & 1 & 3273.5 & 206.59 & $0.86(0.001)$ \\
\hline Location & 1 & 107.5 & 6.78 & $0.03(0.02)$ \\
\hline Site $\mathrm{x}$ location & 1 & 140.9 & 8.89 & $0.04(0.01)$ \\
\hline Residuals & 18 & 285.2 & & 0.07 \\
\hline Total & 21 & 3807.1 & & 1.00 \\
\hline \multicolumn{5}{|l|}{ Analysis II } \\
\hline Pre/post-restoration & 1 & 3.14 & 0.21 & $0.01(0.78)$ \\
\hline Residuals & 17 & 259.14 & & 0.99 \\
\hline Total & 18 & 262.28 & & 1.00 \\
\hline
\end{tabular}




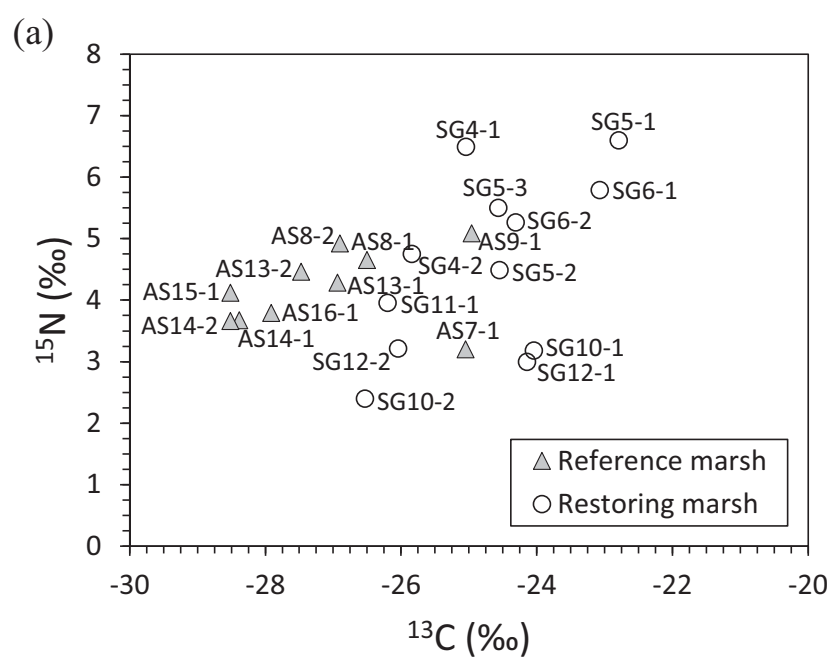

(b)

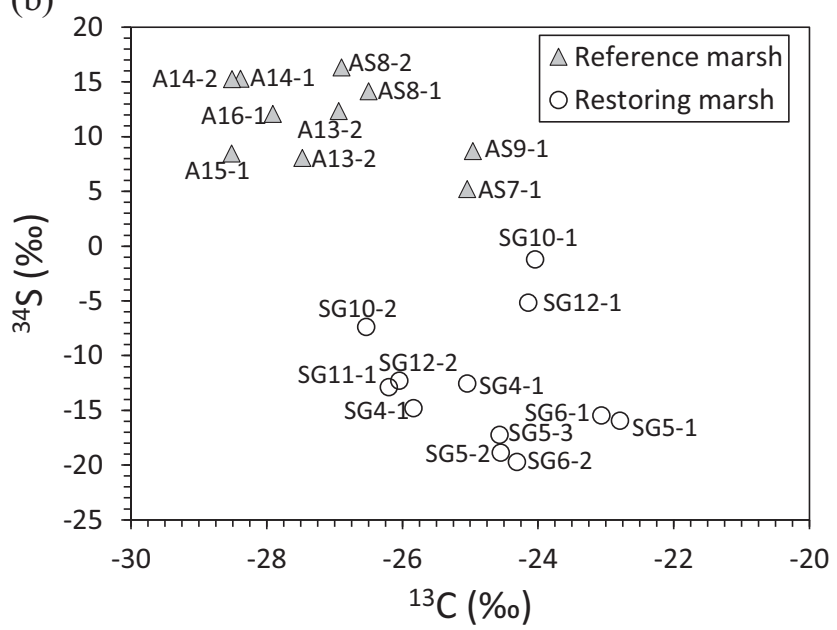

(c)

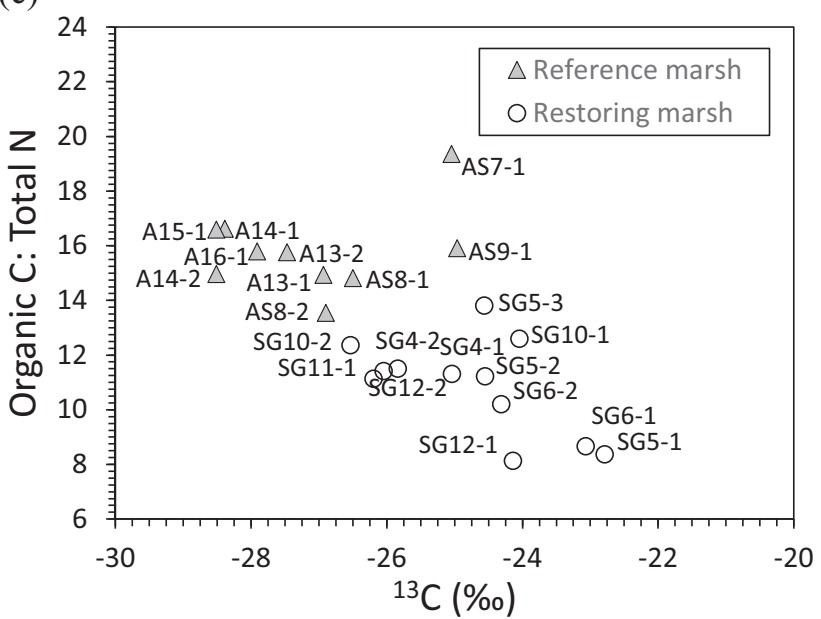

Fig. 3 Biplots of a $\delta^{13} \mathrm{C}$ vs. $\delta^{15} \mathrm{~N}, \mathbf{b} \delta{ }^{13} \mathrm{C}$ vs. $\delta^{34} \mathrm{~S}$, and $\mathbf{c} \delta^{13} \mathrm{C}$ vs. total organic $\mathrm{C}$ : total $\mathrm{N}$ in all $2-\mathrm{cm}$ core sections from the Reference Marsh and Restoring Marsh dated to the post-restoration period. Cores labels include AS (Reference) or SG (Restoring), the core number, and a dash followed by the $2-\mathrm{cm}$ section number. For core locations, see Fig. 1

\section{Model Uncertainty and Sensitivity}

An examination of the results from the original model run and the sensitivity analysis (S1, S2, S3; Online Resource 1: Table S4, Table S5) showed that the dominant carbon sources at each location largely remained stable across all model runs (Fig. 5) even though the Bayesian SIMM could be sensitive to relatively small changes in the stable isotope composition of carbon sources.

At Reference-Inland, the combination of Marsh C3 Plants and Marsh POM contributions represented the majority of autochthonous contributions across all model runs. Both Delta POM and Riverine POM, which both had minor contributions, reached their highest levels $(\sim 20 \%)$ in S2. At Reference-Seaward, Marsh C3 Plants, which had a very high contribution in the original model run $(89 \%)$ remained dominant in all three scenarios (Fig. 5). In comparison to Reference-Inland, Marsh POM represented a smaller contribution to autochthonous sources, reaching over $10 \%$ only in S1. Riverine Plants more than doubled in the three scenarios, reaching the highest contribution (14\%) in $\mathrm{S} 1$ (Online Resource 1: Table S5). Riverine POM, which was inconsequential in the original model increased in all scenarios, peaking at $13 \%$ in S2.

At Restoring-Inland, Riverine POM remained the greatest carbon contributor across all model runs. Riverine Plants and Riverine POM together represented roughly half the total carbon sources in all model runs (Fig. 5). The combination of Marsh C3 Plants and Marsh POM ranged from 20\% (S2) to $32 \%$ (original run) (Online Resource 1: Table S5). At Restoring-Seaward, Marsh POM and Marsh C3 Plants together contributed between 55 and $60 \%$ in all runs except S2 (45\%), with Marsh POM being the greater of the two sources in all runs except S3 (Online Resource 1: Table S5). In contrast to Restoring-Inland, riverine sources at RestoringSeaward were less than $15 \%$ across all model runs. Delta POM was the highest at this location across all runs, reaching up to $35 \%$ in S2.

Overall, the greatest similarity in the dominant carbon sources was found between the original model and S3, which is the scenario representing maximum negative change of core sediments since restoration $\left(\Delta \delta^{13} \mathrm{C}=0.00 \%, \Delta \delta^{15} \mathrm{~N}=-\right.$ $0.48 \%$ ) (Fig. 5). This was true for all locations except Restoring-Seaward, where $\mathrm{S} 1$, the mean change in $\delta^{13} \mathrm{C}$ and $\delta^{15} \mathrm{~N}$ values of core sediments $\left(\Delta \delta^{13} \mathrm{C}=0.29 \%, \Delta \delta^{15} \mathrm{~N}=-\right.$ $0.11 \%$ ), was most similar to the original model. The likely reason that $\mathrm{S} 3$ yielded the most similar results to the original model in three of the four study locations is that $\delta^{13} \mathrm{C}$ did not change at all in this scenario and $-0.48 \%$ o change in $\delta^{15} \mathrm{~N}$ was seemingly not enough to cause a major impact on the results. At Restoring-Seaward, the only location at which Marsh and Delta POM were top contributors, core samples were the most enriched in $\delta^{15} \mathrm{~N}$ (Fig. 2). The reason that $\mathrm{S} 1$ provided the 
Table 3 The estimated contributions of allochthonous, autochthonous, and riverine carbon sources at each study location

\begin{tabular}{llll}
\hline Location & $\begin{array}{l}\text { Allochthonous contributions } \\
(\%)\end{array}$ & $\begin{array}{l}\text { Autochthonous contributions } \\
(\%)\end{array}$ & $\begin{array}{l}\text { Riverine contributions } \\
(\%)\end{array}$ \\
\hline Reference-Inland & 13.02 & 86.98 & 4.05 \\
Reference-Seaward & 7.14 & 92.86 & 4.76 \\
Restoring-Inland & 91.18 & 8.82 & 47.51 \\
Restoring-Seaward & 87.34 & 12.66 & 4.84 \\
\hline
\end{tabular}

most similar results to the original model likely stems from the fact that changes in $\delta^{15} \mathrm{~N}$ values in $\mathrm{S} 2$ and $\mathrm{S} 3$ were greater than in $\mathrm{S} 1$, causing greater deviations from the original model run (Figs. 2 and 5).

We further explored whether model error could potentially be tied to diagenesis of sediments by using the PERMANOVA to compare pre- and post-restoration isotopic compositions at the Reference Marsh. Our analysis showed no significant difference in $\delta^{13} \mathrm{C}, \delta^{15} \mathrm{~N}$, and $\delta^{34} \mathrm{~S}$ signatures between the core sections from 2000 to 2009 and those from 2010 to 2017 (Table 2). This indicates that model error was more likely due to within sample variability than from diagenesis, at least during the period from 2000 to 2017.

\section{Organic Carbon Accumulation Rates in the Restoring vs. Historic Marsh}

Marsh C3 Plants at the Reference Marsh had the highest carbon accumulation rates by a large margin $\left(98 \mathrm{~g} \mathrm{C} \mathrm{m}^{-2}\right.$ year $^{-1}$ at Reference-Inland and $119 \mathrm{~g} \mathrm{C} \mathrm{m}^{-2}$ year $^{-1}$ at ReferenceSeaward; Fig. 6). At Restoring-Inland, Riverine POM (52 g

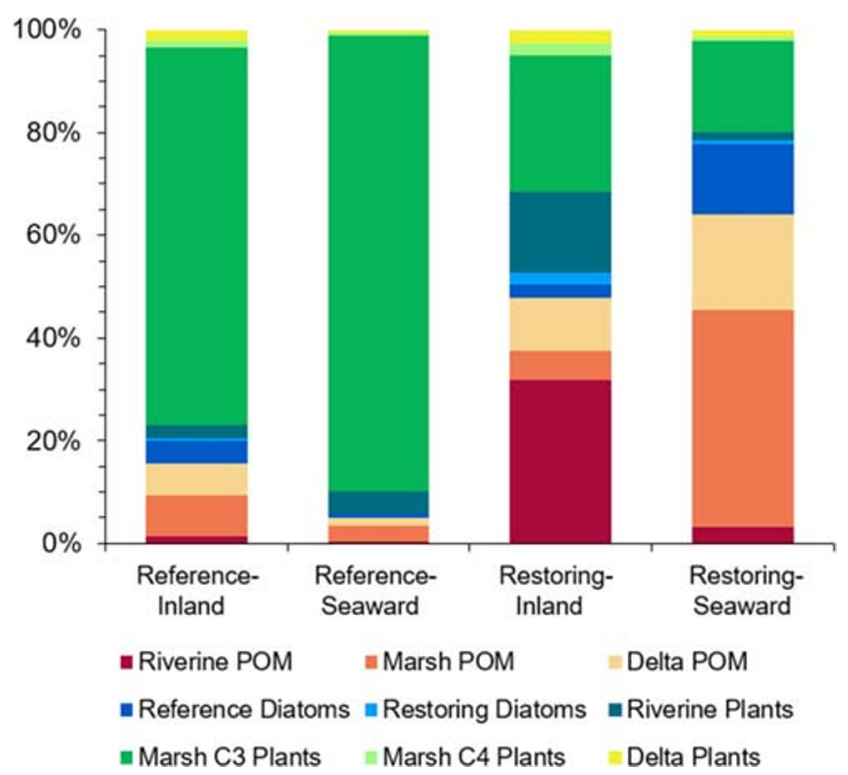

Fig. 4 Relative contributions of organic carbon sources to the blue carbon sediment sinks of Reference-Inland, Reference-Seaward, RestoringInland, and Restoring-Seaward during the post-restoration period determined with IsotopeR, a Bayesian stable isotope mixing model (SIMM)
$\mathrm{C} \mathrm{m}^{-2}$ year $^{-1}$ ) and Marsh C3 Plants (43 $\mathrm{g} \mathrm{C} \mathrm{m}^{-2}$ year $\left.^{-1}\right)$ had the highest rates. Marsh POM (69 $\mathrm{g} \mathrm{C} \mathrm{m}^{-2}$ year $\left.^{-1}\right)$ had the highest rate of carbon accumulation at Restoring-Seaward, followed by Delta POM (30 $\mathrm{g} \mathrm{C} \mathrm{m}^{-2}$ year $^{-1}$ ) and Marsh C3 Plants (29 $\mathrm{g} \mathrm{C} \mathrm{m}^{-2}$ year $\left.^{-1}\right)$.

\section{Discussion}

\section{Carbon Source Contributions}

Our results demonstrate that both the Reference Marsh and Restoring Marsh function as blue carbon sediment sinks, trapping organic carbon originating from marine and freshwater parts of the estuary (Fig. 4, Online Resource 1: Table S3). Both marshes are also receiving grounds for a variety of carbon sources, which is not surprising given the diversity of organic matter produced in estuaries (Odum 1980; Valiela et al. 2000). However, major differences exist between the diversity and quantity of carbon sources found in the sediment sink of each site (Fig. 4, Table 3).

In contrast to food webs, where the $\delta^{13} \mathrm{C}$ signature of consumers and thus their carbon composition is largely determined by diet (Peterson and Fry 1987; Phillips and Gregg 2003; Post 2002), the composition of tidal marsh sediments is determined by environmental factors. One of the most important of these is the abundance of source materials (Ember et al. 1987). At the fully vegetated Reference Marsh, the carbon in the sediments consisted mainly of autochthonous Marsh C3 Plants growing in situ (73\% at Inland and 89\% at Seaward sites, Fig. 4 and Online Resource 1: Table S5), with much of this carbon likely originating from root material, which has a slower decomposition rate relative to aboveground biomass (Hackney and de la Cruz 1980; Craft 2001). Out of the total mean carbon accumulation rate of $134 \pm 19 \mathrm{~g}$ $\mathrm{C} \mathrm{m}^{-2}$ at the Reference Marsh (Drexler et al. 2019), Marsh C3 Plants contributed approximately 98 and $119 \mathrm{~g} \mathrm{C} \mathrm{m}^{-2}$ year $^{-1}$ at Reference-Inland and Reference-Seaward, respectively (Fig. 6). This high autochthonous contribution in carbon accumulation and carbon composition from Marsh C3 Plants contrasts with work in seagrasses in which roughly half of the carbon is from the seagrasses themselves (Kennedy et al. 2010; Greiner et al. 2016; Oreska et al. 2018). 
Fig. 5 Comparison of the relative contributions of carbon sources in the original Bayesian SIMM model $(\mathrm{O})$ vs. scenarios $1-3$ of the sensitivity analysis

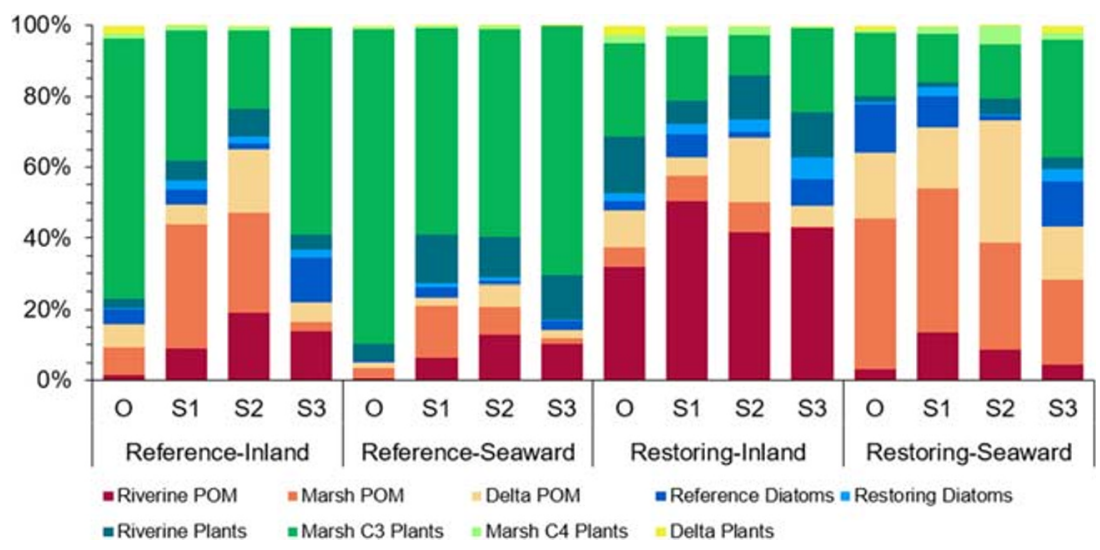

In contrast to the Reference Marsh, carbon sources at the Restoring Marsh were more diverse and dominated by allochthonous contributions (Restoring-Inland: 91; Restoring Seaward: $87 \%$, Table 3). The largest allochthonous contributor to the carbon sink at Restoring-Seaward was Marsh POM, which contributed $42 \pm 34 \%$ or about $69 \mathrm{~g} \mathrm{C} \mathrm{m}^{-2}$ year $^{-1}$ (Figs. 4 and 6) of the total mean carbon accumulation of $164 \pm 54 \mathrm{~g} \mathrm{C} \mathrm{m}^{-2}$ year $^{-1}$ at the site (Drexler et al. 2019). Riverine POM was the largest contributor at RestoringInland representing approximately $32 \pm 41 \%$ or about $52 \mathrm{~g} \mathrm{C}$ $\mathrm{m}^{-2}$ year $^{-1}$.

These results support our first hypothesis, in which we surmised that the carbon sink of the Reference Marsh is comprised of a greater percentage of autochthonous carbon than the Restoring Marsh. Further, although our study was focused on just two reaches in the NRD (Fig. 1), the entire phase III restoration area, which includes the Restoring Marsh, Madrone Slough, and much of the area adjacent to McAllister Creek (Fig. 1), likely has much lower autochthonous carbon production than all the historically unaltered marshes in the NRD. Any largely unvegetated, restoring marsh will likely have low autochthonous production unless, in contrast to this study, it has high productivity of benthic algae (Duarte 2017).
The proximity of allochthonous carbon sources to "receiving grounds" was of major importance in the composition of the sediment carbon sinks at the Reference Marsh and Restoring Marsh. At Restoring-Inland, Riverine POM and Riverine Plants made up almost half of the carbon sources, demonstrating the importance of the adjacent Nisqually River and its tributaries in providing carbon inputs to the marsh (Fig. 4, Table 3). This effect can also be seen in the $\delta^{34} \mathrm{~S}$ values at Restoring-Inland (Online Resource 1: Table S1), which were the most depleted of all the sediment samples, suggesting that the highest contribution of $\delta^{34} \mathrm{~S}$ since restoration was from freshwater sources (Fry 2006; Sharp 2017). At Restoring-Seaward, riverine carbon sources were negligible (Fig. 4, Table 3). Carbon derived from Marsh C3 Plants and POM comprised $60 \%$ of the carbon sink, again indicating that proximity is an important determinant of carbon sink composition. As carbon sources became more distant at both marshes, their relative contributions to the carbon sink decreased. For example, Delta Plants were not important contributors to either the Reference Marsh or the Restoring Marsh. Delta POM, on the other hand, was not important at the Reference Marsh, but did contribute between 10 and $18 \%$ to the Restoring Marsh.
Fig. 6 Estimated carbon accumulation rates for each carbon source in the carbon sediment sink at each study location. POM stands for particulate organic matter. Values were calculated using the mean carbon accumulation rates at the Restoring Marsh (164 g C $\mathrm{m}^{-2}$ year $\left.^{-1}\right)$ and Reference Marsh (134 $\mathrm{g} \mathrm{C} \mathrm{m}^{-2}$ year $^{-1}$ ) determined by Drexler et al. (2019). Error bars are standard deviations from the Bayesian analysis for the relative contribution of each source at each location

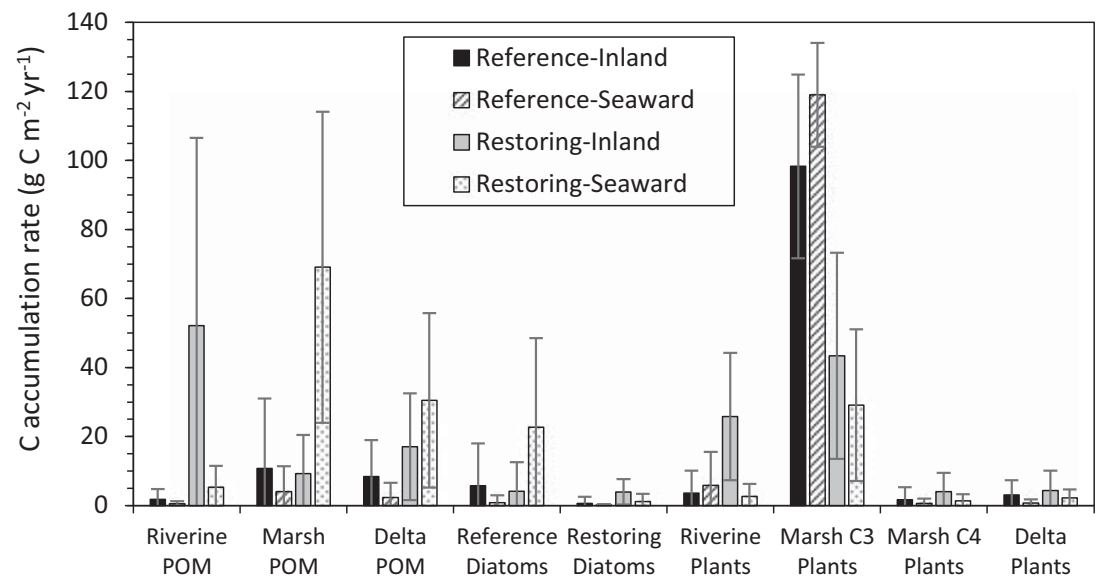


These results support our second hypothesis that the Restoring Marsh acts as a broad receiving ground for carbon, storing a greater relative proportion of different carbon sources than the Reference Marsh. The entire restoring area of phase III likely functions in this manner due to its subsided elevation, bowl shape, and proximity to a wide range of carbon sources. This idea of restoring coastal ecosystems as receiving grounds has only received scant attention in the literature. Howe and Simenstad (2007) demonstrated that mussels in a restoring tidal marsh were receiving organic matter subsidies from a nearby reference tidal marsh. In addition, research in restoring seagrasses has shown that such systems can accumulate allochthonous carbon from a variety of sources, particularly those in closest proximity (Greiner et al. 2016; Oreska et al. 2018).

Hydrodynamics and site geomorphology also likely shaped the composition of the carbon sinks at both marshes in this study, as these factors affect the movement and abundance of materials delivered to and trapped in the sediments of each site (Collins and Kuehl 2001). Because the tidal range at the NRD tops $5 \mathrm{~m}$ (USFWS 2005), there is ample tidal energy to entrain material and transport it into either marsh. The Nisqually River is also an important contributor to the flow regime, particularly during high discharge years, transporting inorganic sediments and carbon sources from the watershed and eroding bank sediments (Ballanti et al. 2017). At the Reference Marsh, allochthonous material is not as readily incorporated into the sediment sink as compared to the Restoring Marsh (Table 3). This may be due to hydrodynamics, suspended sediment concentration, elevation, surface roughness, or other site specific characteristics. The sparse cover of vegetation may make the carbon sink of the Restoring Marsh more vulnerable to erosive loss because plant roots, shoots, and litter are not available to trap material (Cahoon et al. 2006; Kirwan and Megonigal 2013); however, its faster vertical accretion rates (twice that of the Reference Marsh, Drexler et al. 2019) may counteract losses from erosion and decomposition by quickly burying deposited carbon. In addition, benthic microalgae (diatoms), though not a major component of the carbon sink, may serve to bind sediments together with extracellular polymeric substances, thus aiding in carbon burial (McKew et al. 2013; Oakes and Eyre 2014).

\section{Uncertainties}

Once carbon has been buried in sediments, if it remains in place (i.e., is not subject to bioturbation or other means of erosion), the main force acting on it is diagenesis, which is largely controlled by microbial decomposition and depends to a great extent on the reactivity of the carbon source and the ambient sedimentary conditions (Ember et al. 1987; Gonneea et al. 2004). Diagenesis alters the stable isotopic composition of plants and coastal sediments (Freudenthal et al. 2001; Lehmann et al. 2002; Lanari et al. 2018), yet how such changes affect the composition of the carbon sink and how such uncertainty can affect SIMMs are largely unknown. Recent studies have shown that diagenesis can produce changes of $1-2 \%$ o in the stable isotope composition of coastal sediments (particularly in $\delta^{15} \mathrm{~N}$ ) over a period of a few months (Greiner et al. 2016; Jankowska et al. 2016), but no data are available to our knowledge regarding the impact of diagenesis over longer periods. For this reason, we included a sensitivity analysis in our study so that we could examine the impact of different diagenetic scenarios on the Bayesian SIMM (Fig. 5, Online Resources 1: Table S4, Table S5). We found that although small changes in $\delta^{13} \mathrm{C}$ and $\delta^{15} \mathrm{~N}$ values could alter the relative contributions of sources, the main sources of carbon to marsh sediments remained stable throughout all model runs (Fig. 5). Furthermore, our examination of core samples from the Reference Marsh from before and after restoration showed that model sensitivity was more likely to be related to sediment variability than diagenesis (Table 2 ).

Besides diagenesis, there are likely additional sources of uncertainty related to the Bayesian SIMM analysis, which have yet to be quantified. The approach is still somewhat new (Hopkins and Ferguson 2012; Parnell et al. 2013) and only recently has it been applied to sediments instead of food webs. In our study, some proportional source contributions to the carbon sinks of our sites had standard deviations that comprised a significant proportion of the estimated contribution (Online Resource 1: Table S3), suggesting that better separation in isotopic space may have been required to achieve more definitive results. However, it may not be possible to continue redistributing sources into groups beyond a certain point because some combinations of sources simply do not make biological sense in the system under study. Clearly, inclusion of ${ }^{34} \mathrm{~S}$ signatures for all sources and mixtures, had they been available, could have provided additional separation in isospace; however, such ${ }^{34} \mathrm{~S}$ data would not have changed the main results, which focus on the allochthonous vs. autochthonous carbon sources contributing to each marsh (Table 3).

Future work using Bayesian SIMMs to study blue carbon sediments would benefit from comparisons to other approaches including grain size, biomarkers, and eDNA (Leithold and Hope 1999; Prahl et al. 1994; Parnell et al. 2010). For example, Reef et al. (2017) compared eDNA and a Bayesian SIMM (SIAR) in their study of seagrass sediments and found a clearer categorization of sources and a greater contribution of seagrass with the eDNA approach. Such comparisons would go a long way toward helping practitioners clarify the strengths, weaknesses, and uncertainties of Bayesian SIMMs in elucidating the provenance of carbon stored in blue carbon systems. 


\section{Implications for Management}

The results from this study demonstrate that the carbon sink in a restoring salt marsh can be comprised largely of a broad array of allochthonous carbon and that restoring marshes can differ greatly from reference marshes in the composition of their carbon sinks. Both of these results have important implications for using wetland restoration projects as carbon offsets in the carbon market (Crooks et al. 2019). The fact that organic carbon in marsh sediment sinks can originate from estuarine locations beyond marsh boundaries has the potential to create challenges in the allotment of carbon credits for projects in which the geographic boundaries are highly constrained. For example, if important carbon sources are located outside of project boundaries, it may not be possible to adequately study or manage their relative contributions to carbon storage. Further, any project in which the majority of carbon is allochthonous complicates the allotment of carbon credits because, under the widely used Methodology for Tidal Wetland and Seagrass Restoration (VM0033) (Emmer et al. 2015), deduction of allochthonous carbon storage is required unless the project proponent can demonstrate that such carbon would have been lost to the atmosphere as carbon dioxide in the absence of the restoration project. Therefore, in the case of the Restoring Marsh and other sites similar to it, further work would be needed to show that no other receiving ground is available and the stored allochthonous carbon would have been lost as carbon dioxide from the system without the restoration project (Needleman et al. 2019). This shows the difficulty in finding any easy fix for discounting allochthonous carbon contributions to blue carbon systems because such contributions are inextricably tied to the local abundance and proximity of carbon sources.

This study also demonstrates that there is a broader portfolio of coastal lands available for increasing carbon storage on the landscape than previously thought. Our results show that diked, subsided coastal areas, which generally are less desirable for wetland restoration projects, have the potential to provide carbon storage on par with fully vegetated salt marshes if they are in close proximity to carbon sources. Currently, there are many efforts for restoring coastal areas that originally contained salt marshes, but were cut off from tidal flows for decades or even centuries (Roman and Burdick 2012). This study suggests that the range of projects could be expanded to less desirable, subsided coastal areas if a longer unvegetated stage than is typical of salt marsh restorations were acceptable and expected in the restoration trajectory. Such projects would clearly benefit from an assessment of sediment dynamics during restoration planning to assure that local conditions could support marsh building (Ganju 2019). Although these types of projects would likely take longer than usual to reach parity with reference salt marshes, the tradeoff may be worthwhile if society could start benefiting from a reduction in carbon pollution early in the restoration timeline.
Acknowledgments Core collection and analysis were supported by the U.S. Geological Survey (USGS) Land Carbon Program. Biological sample collection and analysis were supported by the Washington State Estuarine and Salmon Restoration Program (ESRP \#13-1583P). We thank Z. Zhu, J. Schmerfeld, and S. Covington for funding this research. We are grateful to J. Orlando for his coring expertise. L. Shakeri, S. Blakely, A. Munguia, L. Lamere, J. Dunn, S. Stout, and A. Cromartie assisted in the field/lab. We appreciate thoughtful reviews by Emily Howe and Matthew Young and comments from Brian Needleman. All core data used in this paper are available in the U.S. Geological Survey National Water Information System. Any use of trade, firm, or product names is for descriptive purposes only and does not imply endorsement by the U.S. Government.

Open Access This article is licensed under a Creative Commons Attribution 4.0 International License, which permits use, sharing, adaptation, distribution and reproduction in any medium or format, as long as you give appropriate credit to the original author(s) and the source, provide a link to the Creative Commons licence, and indicate if changes were made. The images or other third party material in this article are included in the article's Creative Commons licence, unless indicated otherwise in a credit line to the material. If material is not included in the article's Creative Commons licence and your intended use is not permitted by statutory regulation or exceeds the permitted use, you will need to obtain permission directly from the copyright holder. To view a copy of this licence, visit http://creativecommons.org/licenses/by/4.0/.

\section{References}

Appleby, P.G., and F.R. Oldfield. 1978. The calculation of ${ }^{210} \mathrm{~Pb}$ dates assuming a constant rate of supply of unsupported ${ }^{210} \mathrm{~Pb}$ to the sediment. Catena (Supplement) 5 (1): 1-8.

Appleby, P.G., and F.R. Oldfield. 1983. The assessment of ${ }^{210} \mathrm{~Pb}$ data from sites with varying sediment accumulation rates. Hydrobiologia 103 (1): 29-35.

Ballanti, L., K.B. Byrd, I. Woo, and C. Ellings. 2017. Remote sensing for wetland mapping and historical change detection at the Nisqually River Delta. Sustainability 9 (11): 191932 pp.

Belleveau, L.J., J.Y. Takekawa, I. Woo, K.L. Turner, J.B. Barham, J.E. Takekawa, C.S. Ellings, and G. Chin-Leo. 2015. Vegetation community response to tidal marsh restoration of a large river estuary. Northwest Science 89 (2): 136-147.

Bender, M.M. 1971. Variations in the ${ }^{13} \mathrm{C} /{ }^{12} \mathrm{C}$ ratios of plants in relation to the pathway of photosynthetic carbon dioxide fixation. Phytochemistry 10 (6): 1239-1244.

Brooks, K.L., H.L. Mossman, J.L. Chitty, and A. Grant. 2015. Limited vegetation development on a created salt marsh associated with over-consolidated sediments and lack of topographic heterogeneity. Estuaries and Coasts 38 (1): 325-336.

Bull, I.D., P.F. van Bergen, R. Bol, S. Brown, A.R. Gledhill, A.J. Gray, D.D. Harkness, S.E. Woodbury, and R.P. Evershed. 1999. Estimating the contribution of Spartina anglica biomass to saltmarsh sediment using compound specific stable carbon isotope measurements. Organic Geochemistry 30 (7): 477-483.

Burg, M., D.R. Tripp, and E. Rosenberg. 1980. Plant associations and primary productivity of the Nisqually salt marsh on southern Puget Sound, Washington. Northwest Science 54 (3): 222-236.

Cahoon, D.R., P.F. Hensel, T. Spencer, D.J. Reed, K.L. McKee, and N. Saintilan. 2006. Chapter 12: Coastal wetland vulnerability to relative 
sea-level rise: wetland elevation trends and process controls. In Wetlands and Natural Resource Management. Ecological studies, ed. J.T.A. Verhoeven, B. Beltman, R. Bobbink, and D.F. Whigham, vol. 190, 271-292. Berlin: Springer-Verlag.

Chapin, F.S., III, and A.M. Starfield. 1997. Time lags and novel ecosystems in response to transient climate change in arctic Alaska. Climate Change 35 (4): 449-461.

Cloern, J.E., E.A. Canuel, and D. Harris. 2002. Stable carbon and nitrogen isotope composition of aquatic and terrestrial plants of the San Francisco Bay estuarine system. Limnology and Oceanography 47 (3): 713-729.

Collins, M.E., and R.J. Kuehl. 2001. Chapter 6. Organic matter accumulation and organic soils. In Wetland Soils: Genesis, Hydrology, Landscapes, and Classification, ed. J.L. Richardson and M.J. Vespraskas, 301-315. Boca Raton, CRC Press.

Couch, C.A. 1989. Carbon and nitrogen stable isotopes of meiobenthos and their food resources. Estuarine, Coastal and Shelf Science 28 (4): 433-441.

Craft, C.B. 2001. Chapter 5: Biology of wetlands soils. In Wetland Soils: Genesis, Hydrology, Landscapes, and Classification, ed. J.L. Richardson and M.J. Vepraskas, 107-135. Lewis Publishers.

Craft, C.B. 2016a. Ch. 10: Measuring success: performance standards and trajectories of ecosystem development. In Creating and Restoring Wetlands from Theory to Practice, 195-232. Amsterdam: Elsevier.

Craft, C.B. 2016b. Ch. 8: Tidal marshes. In Creating and Restoring Wetlands from Theory to Practice, 195-232. Amsterdam: Elsevier.

Crooks, S., L. Windham-Myers, and T. Troxler. 2019. Ch. 1. Defining blue carbon: the emergence of a climate context for coastal carbon dynamics. In A Blue Carbon Primer: The State of Coastal Wetland Carbon Science, Practice, and Policy, ed. L. Windham-Myers, S. Crooks, and T. Troxler, 1-8. Boca Raton: CRC Press.

Curran, C.A., E.E. Grossman C.S. Magirl, and J.R. Foreman. 2016. Suspended sediment delivery to Puget sound from the lower Nisqually River, Western Washington, July 2010-November 2011, US Geological Survey Scientific Investigations Report 2016-5062, U.S. Geological Survey.

Cutshall, N.H., I.L. Larsen, and C.R. Olsen. 1983. Direct analysis of ${ }^{210} \mathrm{~Pb}$ in sediment samples: Self-absorption corrections. Nuclear Instruments and Methods 306: 309e312.

David, A.T., C.S. Ellings, I. Woo, C.A. Simenstad, J.Y. Takekawa, K.L. Turner, A.L. Smith, and J.E. Takekawa. 2014. Foraging and growth potential of juvenile Chinook salmon after tidal restoration of a large river delta. Transactions of the American Fisheries Society 143 (6): $1515-1529$.

Davis, M.J., I. Woo, C.S. Ellings, S. Hodgson, D.A. Beauchamp, G. Nakai, and S.E. De La Cruz. 2018. Integrated diet analyses reveal contrasting trophic niches for wild and hatchery juvenile chinook salmon in a large river delta. Transactions of the American Fisheries Society 147 (5): 818-841.

Drexler, J.Z., C.C. Fuller, J. Orlando, A. Salas, F.C. Wurster, and J.A. Duberstein. 2017. Estimation and uncertainty of recent carbon accumulation and vertical accretion in drained and undrained forested peatlands of the southeastern USA. Journal of Geophysical Research-Biogeosciences 122: 2563e2579.

Drexler, J.Z., C.C. Fuller, and S. Archfield. 2018. The approaching obsolescence of $137 \mathrm{Cs}$ dating of wetland soils in North America. Quaternary Science Reviews. https://doi.org/10.1016/j.quascirev. 2018.08.028

Drexler, J.Z., I. Woo, C.C. Fuller, and G. Nakai. 2019. Carbon accumulation and vertical accretion in a restored versus historic salt marsh in southern Puget Sound, Washington, United States. Restoration Ecology 27 (5): 1117-1127.

Duarte, C.M. 2017. Reviews and syntheses: hidden forests, the role of vegetated coastal habitats in the ocean carbon budget. Biogeosciences 14 (2): 301-310.
Duarte, C.M., J.L. Iñigo, I.E. Hendriks, I. Mazarrasa, and N. Marbá. 2013. The role of coastal plant communities for climate change mitigation and adaptation. Nature Climate Change 3 (11): 961-968.

Ellings, C.S., M.J. Davis, E.E. Grossman, I. Woo, S. Hodgson, K.L. Turner, G. Nakai, J.E. Takekawa, and J.Y. Takekawa. 2016. Changes in habitat availability for outmigrating juvenile salmon (Oncorhynchus spp.) following estuary restoration. Restoration Ecology 24 (3): 415-437.

Ember, L.M., D.F. Williams, and J.T. Morris. 1987. Processes that influence carbon isotope variations in salt marsh sediments. Marine Ecology Progress Series 36: 33-42.

Emmer, I. Needleman, B., S. Emmet-Mattox, S. Crooks, P. Megonigal, D. Myers, M. Oreska, K. McGlathery, and D. Shoch. 2015. Methodology for tidal wetland and seagrass restoration. Verified Carbon Standard VM0033 Version 1.0, https://verra.org/wpcontent/uploads/2018/03/VM0033-Tidal-Wetland-and-SeagrassRestoration-v1.0.pdf. Accessed 3 May 2019.

Erfanzadeh, R., A. Garbutt, J. Petition, J.P. Maelfait, and M. Hoffmann. 2010. Factors affecting the success of early salt-marsh colonizers: seed availability rather than site suitability and dispersal traits. Plant Ecology 206 (2): 335-347.

Frenkel, R.E., and J.C. Morlan. 1991. Can we restore our salt marshes? Lessons from the Salmon River, Oregon. The Northwest Environmental Journal 7: 119-135.

Freudenthal, T., T. Wagner, F. Wenzhöfer, M. Zabel, and G. Wefer. 2001. Early diagenesis of organic matter from sediments of the eastern subtropical Atlantic: evidence from stable nitrogen and carbon isotopes. Geochimica et Cosmochimica Acta 65 (11): 1795-1808.

Fry, B. 2006. Stable isotope ecology. New York: Springer Science+ Business, Media.

Ganju, N.K. 2019. Marshes are the new beaches: integrating sediment transport into restoration planning. Estuaries and Coasts 42 (4): 917-926.

Gao, J.H., Z.X. Feng, I. Chen, Y.P. Wang, F. Bai, and J. Li. 2016. The effect of biomass variations of Spartina alterniflora on the organic carbon content and composition of a salt marsh in northern Jiangsu Province, China. Ecological Engineering 95: 160-170.

Garbutt, R.A., C.J. Reading, M. Wolters, A.J. Gray, and P. Rothery. 2006. Monitoring the development of intertidal habitats on former agricultural land after the managed realignment of coastal defences at Tollesbury, Essex, UK. Marine Pollution Bulletin 53 (1-4): 155164.

Gonneea, M.E., A. Paytan, and J.A. Herrera-Silveira. 2004. Tracing organic matter sources and carbon burial in mangrove sediments over the past 160 years. Estuarine, Coastal and Shelf Science 61 (2): 211-227.

Greiner, J.T., G.M. Wilkinson, K.J. McGlathery, and K.A. Emergy. 2016. Sources of sediment carbon sequestered in restored seagrass meadows. Marine Ecology Progress Series 551: 95-105.

Hackney, C.T., and A.A. de la Cruz. 1980. In situ decomposition of roots and rhizomes of two tidal marsh plants. Ecology 61 (2): 226-231.

Haltiner, J., J.B. Zedler, K.E. Boyer, G.D. Williams, and J.C. Calloway. 1997. Influence of physical processes on the design, functioning and evolution of restored tidal wetlands in California (USA). Wetlands Ecology and Management 4 (2): 73-91.

Hargis, T.G., and R.R. Twilley. 1994. Improved coring device for measuring soil bulk density in a Louisiana deltaic marsh. Journal of Sediment Research Section A: Sedimentary Petrology and Processes 64 (3a): 681-683.

Hobbs, R.J., E. Higgs, and J.A. Harris. 2009. Novel ecosystems: implications for conservation and restoration. Trends in Ecology \& Evolution 24 (11): 599-605.

Hobbs, R.J., E.S. Higgs, and C.M. Hall. 2013. Chapter 6. Defining novel ecosystems. In Novel ecosystems: intervening in the new ecological world order, ed. R.J. Hobbs, 58-60. Chichester: Wiley-Blackwell. 
Hopkins, J.B., III, and J.M. Ferguson. 2012. Estimating the diets of animals using stable isotopes and a comprehensive Bayesian mixing model. PLoS One 7 (1): e28478. https://doi.org/10.1371/journal. pone.0028478.

Hopkins, J.B. III, J.M. Ferguson. 2015. IsotopeR 0.5, https://cran.rproject.org/web/packages/IsotopeR/vignettes/IsotopeR.pdf. Accessed 8 April 2019.

Howe, E.R., and C.A. Simenstad. 2007. Restoration trajectories and food web linkages in San Francisco Bay's estuarine marshes: a manipulative translocation experiment. Marine Ecology Progress Series 351: 65-76.

Howe, E.R., and C.A. Simenstad. 2015. Using isotopic measures of connectivity and ecosystem capacity to compare restoring and natural marshes in the Skokomish River Estuary, WA, USA. Estuaries and Coasts 38 (2): 639-658.

Hubas, C., C. Passarelli, and D.M. Paterson. 2018. Microphytobenthic biofilms: composition and interactions. In Mudflat ecology. Aquatic ecology series, ed. P. Beninger, vol. 7, 63-90. Springer: Cham.

Jankowska, E., L.N. Michel, A. Zaborska, and M. WlodarskaKowalczuk. 2016. Sediment carbon sink in low-density temperate eelgrass meadows (Baltic Sea). Journal of Geophysical Research Biogeosciences 121 (12): 2918-2934.

Kendall, C., S.R. Silva, and V.J. Kelly. 2001. Carbon and nitrogen isotopic compositions of particulate organic matter in four large river systems across the United States. Hydrological Processes 15 (7): $1301-1346$

Kennedy, J., J. Beggins, C.M. Duarte, J.W. Fourqurean, M. Holmer, N. Marbá, and J.J. Middelburg. 2010. Seagrass sediments as global carbon sink: isotopic constraints. Global Biogeochemical Cycles 24 (4): $1-8$

Kirwan, M.L., and J.P. Megonigal. 2013. Tidal wetland stability in the face of human impacts and sea-level rise. Nature 504 (7478): 53-60.

Lanari, M., M.C. Claudino, A.M. Garcia, and M. da Silva Copertino. 2018. Changes in the elemental $(\mathrm{C}, \mathrm{N})$ and isotopic $\left(\delta^{13} \mathrm{C}, \delta^{15} \mathrm{~N}\right)$ composition of estuarine plants during diagenesis and implications for ecological studies. Journal of Experimental Marine Biology and Ecology 500: 46-54.

Lehmann, M.F., S.M. Bernasconi, A. Barbieri, and J.A. McKenzie. 2002. Preservation of organic matter and alteration of its carbon and nitrogen isotope composition during simulated and in situ early sedimentary diagenesis. Geochimica et Cosmochimica Acta 66: 3573-3584.

Leithold, E.L., and R.S. Hope. 1999. Deposition and modification of a flood layer on the northern California shelf: Lessons from and about the fate of terrestrial particulate organic carbon. Marine Geology 154 (1-4): 183-195

McKew, B.A., A.J. Dumbrell, J.D. Taylor, T.J. McGenity, and G.J.C. Underwood. 2013. Differences between aerobic and anaerobic degradation of microphytobenthic biofilm-derived organic matter within intertidal sediments. FEMS Microbiology Ecology 84 (3): 495509

McLeod, E., G.L. Chmura, S. Buillon, R. Salm, M. Bjork, C.M. Duarte, C.E. Lovelock, W.H. Schlesinger, and B.R. Silliman. 2011. A blueprint for blue carbon: toward an improved understanding of the role of vegetated coastal habitats in sequestering $\mathrm{CO}_{2}$. Frontiers in Ecology and the Environment 9 (10): 552-560.

Moore, J.W., and B.X. Semmens. 2008. Incorporating uncertainty and prior information into stable isotope mixing models. Ecology Letters 11 (5): 470-480.

Mossman, H.L., M.J.H. Brown, A.J. Davy, and A. Grant. 2012. Constraints on salt marsh development following managed coastal alignment: dispersal limitation or environmental tolerance? Restoration Ecology 20 (1): 65-75.

Murtagh, F., and P. Legendre. 2014. Ward's hierarchical agglomerative clustering method: which algorithms implement Ward's criterion? Journal of Classification 31 (3): 274-295.
Needleman, B.A., I.M. Emmer, M.P. Oreska, and J.P. Megonigal. 2019. Ch. 20. Blue carbon accounting for carbon markets. In A Blue Carbon Primer: The State of Coastal Wetland Carbon Science, Practice, and Policy, ed. L. Windham-Myers, S. Crooks, and T. Troxler, 283-292. Boca Raton: CRC Press.

O'Leary, M.H. 1988. Carbon isotopes in photosynthesis. BioScience 38 (5): $328-336$.

Oakes, J.M., and B.D. Eyre. 2014. Transformation and fate of microphytobenthos carbon in subtropical, intertidal sediments: potential for long-term carbon retention revealed by ${ }^{13} \mathrm{C}$-labeling. Biogeosciences 11 (7): 1927-1940.

Odum, E.P. 1980. The status of three ecosystem-level hypotheses regarding salt marsh estuaries: tidal subsidy, outwelling and detritus-based food chains. In Estuarine Perspectives, ed. V.S. Kennedy, 485-495. Cambridge: Academic Press.

Oreska, M.P.J., G.M. Wilkinson, K.J. McGlathery, M. Most, and B.A. McKee. 2018. Non-seagrass carbon contributions to seagrass sediment blue carbon. Limnology and Oceanography 63 (S1): S3-S18.

Orr, M., S. Crooks, and P.B. Williams. 2003. Will restored tidal marshes be sustainable? San Francisco Estuary and Watershed Science 1 (1): $5 \mathrm{http}: / /$ repositories.cdlib.org/jmie/sfews/vol1/iss1/art5.

Parnell, A.C., R. Inger, S. Bearhop, and A.L. Jackson. 2010. Source partitioning using staple isotopes: coping with too much variation. PLoS One 5: e9672. https://doi.org/10.1371/journal.pone.0009672.

Parnell, A.C., D. L. Phillips, S. Bearhop, B.X. Semmens, E.J. Ward, J.W. Moore, A.L. Jackson, J. Grey, D.J. Kelly, and R. Inger. 2013. Bayesian stable isotope mixing models. Environmetrics 24: 387 399.

Peterson, B.J., and B. Fry. 1987. Stable isotopes in ecosystem studies. Annual Review of Ecology and Systematics 18 (1): 293-320.

Phillips, D.L., and J.W. Gregg. 2003. Source partitioning with stable isotopes: coping with too many sources. Oecologia 136 (2): $261-$ 269.

Poppe, K.L., and J.M. Rybczyk. 2019. A blue carbon assessment for the Stillaguamish River estuary: quantifying the climate benefits of tidal marsh restoration. Summary report prepared by Western Washington University for Washington Sea Grant and the nature conservancy. https://salishsearestoration.org/images/6/6f/Poppe_\% 26 Rybczyk 2019 port susan blue carbon.pdf. Accessed 21 October, 2019.

Portnoy, J.W. 1999. Salt marsh diking and restoration: biogeochemical implications of altered wetland hydrology. Environmental Management 24 (1): 111-120.

Portnoy, J.W., and A.E. Giblin. 1997. Effects of historic tidal restrictions on salt marsh sediment chemistry. Biogeochemistry 36 (3): 275-303.

Post, D.M. 2002. Using stable isotopes to estimate trophic position: models, methods, and assumptions. Ecology 83 (3): 703-718.

Prahl, F.G., J.R. Ertel, M.A. Goñi, M.A. Sparrow, and B. Eversmeyer. 1994. Terrestrial organic carbon contributions to sediments on the Washington margin. Geochimica et Cosmochimica Acta 58 (14): 3035-3048.

Prasad, M.B.K., A. Kumar, A.L. Ramanthan, and D.K. Datta. 2017. Sources and dynamics of sedimentary organic matter in Sundarban mangrove estuary from indo-Gangetic delta. Ecological Processes 6 (1): 8. https://doi.org/10.1186/s13717-017-0076-6.

Rabenhorst, M.C. 2001. Chapter 13. Soils of tidal and fringing wetlands. In Wetland Soils: Genesis, Hydrology, Landscapes, and Classification, ed. J.L. Richardson and M.J. Vespraskas, 301-315. Boca Raton: CRC Press.

Reef, R., T.B. Atwood, J. Samper-Villarreal, M.F. Adame, E.M. Sampayo, and C.E. Lovelock. 2017. Using eDNA to determine the source of organic carbon in seagrass meadows. Limnology and Oceanography 62 (3): 1254-1265.

Roman, C.T., and D.M. Burdick. 2012. Ch. 1. A synthesis of research and practice on restoring tides to salt marshes. In Tidal Marsh 
Restoration: A Synthesis of Science and Management, ed. C.T. Roman and D.M. Burdick, 3-10. Washington: Island Press.

Santos, R., N. Duque-Nuñez, C. de los Santos, M. Martins, A.R. Carrasco, and C. Veiga-Pires. 2018. Superficial sedimentary stocks and sources of carbon and nitrogen in coastal vegetated assemblages along a flow gradient. Scientific Reports. https://oi.org/10.1038/ s41598-018-37031-6.

Shared Strategy for Puget Sound. 2007. Puget Sound Salmon Recovery Plan-Volume 1, National Oceanic and Atmospheric Administration. https://www.psp.wa.gov/shared-salmon-strategy/ index.htm .

Sharp, Z.D. 2017. Principles of stable isotope geochemistry. 2nd ed. https://doi.org/10.5072/FK2GB24S9F https://digitalrepository. unm.edu/unm_oer/1. Accessed 1 April 2019.

U.S. Fish and Wildlife Service (USFWS). 2005. Nisqually National Wildlife Refuge final comprehensive conservation plan. Nisqually National Wildlife Refuge Complex, US Fish and Wildlife Service. https://catalog.data.gov/dataset/nisqually-national-wildlife-refugefinal-comprehensive-conservation-plan.

Valiela, I., M.L. Cole, J. McClelland, J. Hauxwell, J. Cebrain, and S.B. Joye. 2000. Role of salt marshes as part of coastal landscapes. In Concepts and Controversies in Tidal Marsh Ecology, ed. M.P. Weinstein and D.A. Kreeger, 22-38. Dordrecht: Kluwer.

Van Metre, P.C., and C.C. Fuller. 2009. Dual-core mass-balance approach for evaluating mercury and $210 \mathrm{~Pb}$ atmospheric fallout and focusing to lakes. Environmental Science \& Technology 43: 26e32.
Vanderklift, M.A., R. Marcos-Martinez, J.R.A. Butler, M. Coleman, A. Lawrence, H. Prislan, D.L.A. Steven, and S. Thomas. 2019. Constraints and opportunities for market-based finance for the restoration and protection of blue carbon ecosystems. Marine Policy. https://doi.org/10.1016/j.marpol.2019.02.001.

Windham-Myers, L., S. Crooks, and T.G. Troxler. 2019. Glossary. In A blue carbon primer: the State of Coastal Wetland Carbon Science, Practice, and Policy, ed. L. Windham-Myers, S. Crooks, and T.G. Troxler, xxv-xxvii. Boca Raton: CRC Press.

Wolters, M., A. Garbutt, R.M. Bekker, J.P. Bakker, and P.D. Carey. 2008. Restoration of salt-marsh vegetation in relation to site suitability species pool and dispersal traits. Journal of Applied Ecology 45 (3): 904-912.

Woo, I., M.J. Davis, C.S. Ellings, G. Nakai, J.Y. Takekawa, and S. De La Cruz. 2018. Enhanced invertebrate prey production following estuarine restoration supports foraging for multiple species of juvenile salmonids (Oncorhynchus spp.). Restoration Ecology 26 (5): 964 975.

Woo, I., M.J. Davis, C.S. Ellings, S. Hodgson, J. Takekawa, G. Nakai, and S. De La Cruz. 2019. A mosaic of estuarine habitat types with prey resources from multiple environmental strata supports a diversified foraging portfolio for juvenile Chinook salmon. Estuaries and Coasts 42 (7): 1938-1954.

Xue, B., C. Yan, H. Lu, and Y. Bai. 2009. Mangrove-derived organic carbon in sediment from Zhangiiang estuary (China) mangrove wetland. Journal of Coastal Research 25 (4): 949-956. 